CIGS The Canon Institute for Global Studies

CIGS Working Paper Series No. 20-005E

\title{
Recurrent Bubbles and Economic Growth
}

Pablo A. Guerron-Quintana (Boston College and Espol)

Tomohiro Hirano (Royal Holloway, University of London and Center for

Macroeconomics, London School of Economics /

Canon Institute for Global Studies)

Ryo Jinnai (Hitotsubashi University)

※Opinions expressed or implied in the CIGS Working Paper Series are solely those of the author, and do not necessarily represent the views of the CIGS or its sponsor.

※CIGS Working Paper Series is circulated in order to stimulate lively discussion and comments.

※Copyright belongs to the author(s) of each paper unless stated otherwise. 


\title{
Recurrent Bubbles and Economic Growth*
}

\author{
Pablo A. Guerron-Quintana ${ }^{\dagger} \quad$ Tomohiro Hirano Ryo Jinnai $^{\ddagger}$ \\ May 7, 2020
}

\begin{abstract}
We study a regime-switching recurrent bubble model with endogenous growth. The economy experiences both bubbly and bubbleless regimes recurrently. Infinitely lived households expect future bubbles, which crowds out investment and reduces economic growth. Because realized bubbles crowd in investment, their overall impact on economic growth and welfare crucially depends on both the level of financial development and the frequency of bubbles. We examine the U.S. economic data through the lens of our model, finding evidence of recurrent bubbles. Furthermore, counterfactual simulations suggest that 1) the IT and housing bubbles together lifted U.S. GDP by almost 2 percentage points permanently; and 2) the U.S. economy could have grown even faster if people had believed that asset bubbles would not arise.
\end{abstract}

\section{Introduction}

A decade after the Great Recession, economic observers seem to agree on a few points. First, an asset price bubble emerged in the years leading up to the crisis. Second, the implosion of this bubble triggered a financial crisis, resulting in severe contraction (Brunnermeier and Oehmke

\footnotetext{
${ }^{*}$ We are thankful to Dongho Song for extensive discussions and feedback. We also benefited from useful comments by Levent Altinoglu, Gadi Barlevy, Susanto Basu, Fernando Broner, Bernard Dumas, Andrew Foerster, Masashige Hamano, Takashi Kamihigashi, Michihiro Kandori, Nobuhiro Kiyotaki, Nan Li, Alberto Martin, Kiminori Matsuyama, Masaya Sakuragawa, Jose Scheinkman, Joseph Stiglitz, Jean Tirole, Vincenzo Quadrini, Rosen Valchev, Jaume Ventura, and seminar participants at Aoyama Gakuin University, Bank of Canada, Bank of Japan, Beijing University, Boston College, Canon Institute for Global Studies, CREI, Emory, Espol, Hitotsubashi University, Japan Center for Economic Research, Keio University, Kobe University, Michigan State University, Monash University, Norwegian Business School, Okayama University, Osaka University, RIETI, Royal Holloway, University of London, Shanghai Jiao Tong University, Tokai University, Tohoku University, University of Birmingham, University of Tokyo, Waseda University, Wuhan University, and the NBER Summer Institute. A part of this work is supported by JSPS Kakenhi 18H00831 and 18KK0361.

${ }^{\dagger}$ Boston College and Espol, pguerron@gmail.com

${ }^{\ddagger}$ Royal Holloway, University of London and Center for Macroeconomics, London School of Economics and Canon Institute for Global Studies, tomohih@gmail.com

${ }^{\S}$ Hitotsubashi University, rjinnai@ier.hit-u.ac.jp
} 
(2013)). Third, the recovery has been lackluster, with GDP growing about 1 percentage point slower after the crisis. Interestingly, recent empirical studies find that these features are common to other financial crises, and moreover, these bubble-driven financial crises are not extremely rare but recur over time with an interval of a few decades in many cases; see Cerra and Saxena (2008), Blanchard, Cerutti, and Summers (2014), and Jorda, Schularick, and Taylor (2015), as well as Kindleberger (2001). Motivated by these empirical findings, this paper studies the economic implications of recurrent bubbles and their crashes.

We construct a tractable model of recurrent bubbles with endogenous growth. Because of financial frictions, investors are unable to obtain funds as they wish. Bubbles may mitigate the lack of funding problem, speeding up capital accumulation, which in our endogenous growth model speeds up economic growth too. This is the so-called crowding-in effect of realized bubbles. We introduce regime switches to this framework. There are two regimes: a "fundamental regime" and a "bubbly regime." The fundamental regime is characterized by the absence of bubbles (bubbleless). When the economy switches to the other regime, a new vintage of bubbly assets is provided to households. ${ }^{1}$ A sunspot determines whether the economy is in the fundamental regime or the bubbly regime. In this environment, we show that there is an interesting equilibrium in which asset price bubbles arise recurrently, and crash recurrently.

Our model features a novel crowding-out effect of future bubbles. Households are long-lived and hence experience the emergence and the collapse of bubbles recurrently. Importantly, they fully anticipate these dynamics. That is, even if bubbles are absent today, households expect their emergence in the future. Likewise, when bubbles exist, households rationally anticipate their future collapse and re-emergence. These expectations about future bubbles affect households' decisions, and, crucially, are a drag on economic growth. The underlying mechanism is the familiar wealth effect. Households will be wealthier when bubbles arise in the future. With this anticipation, households increase both consumption and leisure, which reduces both investment and economic growth today. ${ }^{2}$

The recent development in the macroeconomics of asset price bubbles, including Kocherlakota (2009), Farhi and Tirole (2012), and Hirano and Yanagawa (2017), considered non-recurrent bubbles. That is, bubbles collapse once and for all, and re-emergence of asset price bubbles is not expected at all. In this framework, the economy is completely free from the influence of bubbles after their collapse. Therefore, the cost-benefit analysis of non-recurrent bubbles requires an in-

\footnotetext{
${ }^{1}$ Following the literature, we consider bubbly assets that contribute neither to production nor to households' utility. In other words, we consider pure bubbles. Modeling bubbles attached to real assets is perhaps more realistic, but it is technically difficult and this is well known in the literature. See Santos and Woodford (1997) for details. An interesting paper by Pham, Le Van, and Bosi (2019) takes a step toward it.

${ }^{2}$ A crowding-out effect of asset bubbles has been discussed in the existing literature (Kocherlakota (2009), Farhi and Tirole (2012), and Hirano and Yanagawa (2017)), but strictly speaking, it is the crowding-out effect of realized bubbles. Our model has this effect too. But we emphasize that our model has the crowding-out effect of future bubbles as well, and this type of crowding-out effect is absent in the existing literature in which asset bubbles are not recurrent.
} 
spection of the economy during the bubbly period alone. ${ }^{3}$ However, if bubbles are recurrent, we have to examine the economy after their collapse too. This is so because even though bubbles are absent, households' actions are still influenced by unrealized bubbles. The economy in which bubbles are expected to arise in the future is crucially different from the economy in which they are not. Specifically, even the bubbleless growth is slowed by the expectation of future bubbles; it is slower in our recurrent-bubble economy than in an alternative economy in which bubbles neither exist nor are expected to arise in the future, which is exactly the situation after the crash in the models with non-recurrent bubbles.

Because the crowding-in effect of realized bubbles and the crowding-out effect of future bubbles compete with each other, the welfare impact of recurrent bubbles depends on the level of financial development and the frequency of bubbles. ${ }^{4}$ If the economy's financial market is severely underdeveloped, the crowding-in effect of realized bubbles tends to dominate. Hence, recurrent bubbles enhance average growth and improve welfare over the long run. In contrast, if the financial market is relatively developed, the crowding-out effect of future bubbles can dominate, and recurrent bubbles reduce average growth and welfare over the long run. Moreover, if bubbles emerge more frequently, the crowding-out effect becomes stronger because households start to "count on" future bubbles more strongly. Therefore, high-frequency bubbles may not be desirable even in financially under developed economies, not to mention financially developed ones.

We examine the U.S. data for the period 1984-2017 through the lens of our model. In particular, we identify bubbles by exploiting the model's robust predictions that both GDP growth and the stock-market-to-GDP ratio are high when bubbles exist. Using these observables, we uncover evidence of recurrent bubbles; specifically, at least two bubbly episodes are very likely in our sample: the first one from around 1997 to 2001, and the second one from around 2006 to the onset of the Great Recession. The asset market was strong in these periods, and GDP growth was robust too. Our model attributes these observations to the emergence of bubbles. But not all the booms are estimated to be "bubbly." For example, our model attributes the strong growth in the mid-1990s to favorable productivity shocks.

\footnotetext{
${ }^{3}$ More precisely, the macroeconomic impact of non-recurrent bubbles depends on the crowding-in and the crowding-out effects of realized bubbles alone. If the crowding-in effect dominates, the economy has a boom in the bubbly period, and vice versa. Another caveat exists; after the collapse of bubbles, the economy converges to the bubble-less steady-state monotonically, and this is standard in the literature. With these conditions, the overall macroeconomic impact of asset bubbles depends on the bubbly period alone; bubbles are good for the economy if they are expansionary, and vice versa.

${ }^{4}$ On the welfare impact of asset bubbles, the classic argument is that bubbles improve welfare because they help consumption smoothing (see Samuelson (1958), Bewley (1980), Scheinkman and Weiss (1986), Farhi and Tirole (2012), and Hirano and Yanagawa (2017)). We believe that this argument captures an important aspect of asset bubbles, but we take a different route and shed a new light on the topic. In our model, asset bubbles do not help consumption smoothing because income risks from idiosyncratic shocks are perfectly shared among members of a large household even without bubbles. We find that in this setup, the welfare impact of asset bubbles depends crucially on their growth impact. We also find a new tradeoff; that is, the expectation about future bubbles is a headwind to growth, and this hidden cost makes the welfare impact of recurrent bubbles non-trivial even if the crowding-in effect of realized bubbles dominates the crowding-out effect of realized bubbles.
} 
Our model provides a plausible explanation of the growth slowdown over the past decade. To the extent that the 2000s were a period with asset price bubbles, the collapse of these bubbles led inevitably to slower growth. Furthermore, growth will remain depressed until a new bubble emerges in the economy, which has not occurred according to our estimates.

A counterfactual simulation reveals that the U.S. economy benefited from the realized bubbles for two reasons. First, the economy boomed during the bubbly episodes. Second, the growth acceleration during the bubbly episodes has a permanently positive impact on the output level even after bubbles are gone. We estimate that the two bubbly episodes combined permanently raised the level of U.S. GDP by about 2 percentage points. However, another counterfactual simulation suggests that the U.S. economy could have grown even faster. That is, if the economy were in a different equilibrium in which bubbles never arose and were never expected to emerge, GDP growth would be higher than the actual on average. This is because the crowding-out effect of future bubbles is absent.

The rest of the paper proceeds as follows. Next, we highlight the contributions of our paper to the existing literature. Then we describe the baseline model in Section 3. Section 4 discusses calibration. In Section 5, we discuss the impacts of recurrent bubbles on growth and welfare. The empirical results with a discussion of the last several decades and the Great Recession are in Section 6. Section 7 concludes.

\section{Related Work in the Literature}

This paper studies asset bubbles in an infinite horizon economy. In this regard, our paper is related to the seminal work by Bewley (1980), Scheinkman and Weiss (1986), Woodford (1990), Kocherlakota (1992, 2009), and Kiyotaki and Moore (2019). ${ }^{5}$ These studies examined non-recurrent bubbles, while we focus on recurrent bubbles. ${ }^{6}$ Kamihigashi (2011) is probably the earliest paper studying recurrent bubbles in infinite horizon economies. He provides sufficient conditions for a bubble process to be recurrent in a partial equilibrium model without production. Neither investment nor labor supply is endogenous in his model. In contrast, we study recurrent bubbles in a dynamic general equilibrium model with production, financial frictions, and endogenous growth.

\footnotetext{
${ }^{5}$ Kocherlakota (1992) explicitly derived the economic conditions for which asset bubbles can arise in infinite horizon economies in a manner fully consistent way with the transversality condition. He showed in an endowment economy that if bubbles exist at any date, then everyone faces borrowing constraints that bind currently or at some point in the future. Furthermore, the economy needs to grow as fast as bubbles, so that agents can always afford to buy the bubbly asset. As in Kocherlakota (1992), in our model, on the balanced growth path with positive bubbles, the liquidity constraint and the short-sale constraint bind, and the economy grows at the same rate as the bubbles. See Kocherlakota (1992) for a more general discussion including consistency with the Transversality condition.

${ }^{6}$ The same applies to the landmark papers on rational bubbles in an overlapping generations model including Samuelson (1958), Shell, Sidrauski, and Stiglitz (1969, Section 3), Townsend (1980), Tirole (1985), Diba and Grossman (1988), and Farhi and Tirole (2012); they examined non-recurrent bubbles.
} 
Martin and Ventura (2012) study recurrent bubbles in an overlapping generations model in which agents live for only two periods. In their model, everyone supplies one unit of labor inelastically in the young period, and consumes only in the old period. These assumptions make expectations about future bubbles irrelevant to labor supply, consumption, and investment in the young period. As a result, their recurrent-bubble model is essentially the same as Weil (1987)'s stochastic-bubble model. In his setup, bubbles are expected to collapse once and for all, and reemergence of asset bubbles is not expected at all. In contrast, our model has infinitely lived agents, and their expectations about future bubbles do affect labor supply, consumption, and investment, as well as long-run economic growth and welfare.

Gali (2014) and Miao, Wang, and Xu (2015) study a rational-bubble model in which only a fraction of the existing bubbles collapse every period. But new bubbles are created right away. Under these assumptions, they study the model's local dynamics around the bubbly steady state with a standard linearization method. Our analysis is distinct from theirs in two important dimensions. First, we work with a regime-switching model in which regime switches are associated with the emergence and the collapse of bubbles. In addition, regime switches move the steady state itself. Because the regime-dependent steady states are obtained from the original nonlinear model, solved globally, this approach allows us to assess the effect of recurrent bubbles accurately. ${ }^{7}$ Second, we consider the complete collapse of bubbles. Crucially, this difference is important both quantitatively and qualitatively. In the appendix, we examine variants of our regime-switching model in which the collapse is partial. In such a model, when a fraction of the bubbly assets lose their valuation (partial collapse), the demand for the rest of the bubbly assets rises because liquid assets become scarce. Their prices are therefore pushed up, which can endogenously mitigate the adverse impact of the partial collapse even if most of the existing bubbly assets lose their valuations. In other words, the effect of the complete collapse of bubbles is unable to be accurately assessed without formally modeling it because the recurrent-bubble model with multiple entire collapses (our model) behaves very differently from the recurrent-bubble model with multiple partial collapses.

The non-linearity flavor of our model is related to Mendoza (2010), Brunnermeier and Sannikov (2014), He and Krishnamurthy (2013), Matsuyama (2013), Matsuyama, Sushko, and Gardini (2016), Gertler and Kiyotaki (2015), and Gertler, Kiyotaki, and Prestipino (2020). All of these papers solve the models using global techniques. In Mendoza (2010), Brunnermeier and Sannikov (2014), and He and Krishnamurthy (2013), relatively large shocks cause the economy to jump far away from the steady state, resulting in highly non-linear effects. In Matsuyama (2013) and Matsuyama, Sushko, and Gardini (2016), even without any shocks, the economy exhibits high

\footnotetext{
${ }^{7}$ Finding regime-dependent steady states is difficult in general. But in our model, endogenous productivity simplifies the analysis. Namely, once we detrend the model using capital, the equilibrium conditions depend only on the exogenous states of the economy, and we can find the regime-dependent steady states in the detrended model easily. See the appendix for details.
} 
levels of non-linearity, generating endogenous cycles. In Gertler and Kiyotaki (2015), and Gertler, Kiyotaki, and Prestipino (2020), discontinuous macroeconomic effects are generated by a bank run, which is the entire collapse of the banking sector in their models. All of these papers emphasize that the local analysis around the steady state may not be suitable to account for large events like financial crises, because it may not be able to capture important non-linearities in the events.

Our work is also related to the recent papers emphasizing the downside of asset bubbles. This is interesting research because there is a concern that the theoretical literature on bubbles traditionally emphasizes their upside disproportionately and, as a result, does not address the types of issues policymakers care most about (Barlevy (2018)). Specifically, Allen, Barlevy, and Gale (2017) and Biswas, Hanson, and Phan (2018) show that stagnation in output occurs after the bursting of bubbles in models without growth. Because the stagnation in output is costly, it makes the welfare impact of bubbles non-trivial even if bubbles raise the output level when they are present. Their arguments, however, hinge on mechanisms that are not necessarily related to bubbles. For example, Allen, Barlevy, and Gale introduce default costs exogenously associated with the collapse of bubbles. Biswas, Hanson, and Phan introduce downward nominal wage rigidities. Our model abstracts from such mechanisms or other frictions, including nominal price rigidities or fire-sale externalities. We show that even in the absence of such frictions, an interesting cost still emerges, and it is closely related to expectations about future bubbles.

Hirano and Yanagawa (2017) study rational bubbles in an endogenous growth model with financial frictions. But they study the stochastic bubbles à la Weil (1987), whereas we study recurrent bubbles. In addition, the role of bubbles is also different. Hirano and Yanagawa emphasize the speculative aspect of bubbles; agents buy and sell bubbly assets because they provide a high rate of return. In contrast, we emphasize the liquidity role of bubbly assets. Our formulation is based on Kiyotaki and Moore (2019), who model deteministic fiat money as a liquid asset. Guerron-Quintana and Jinnai (2019) examine the causes of the post-war U.S. recessions through the lens of a dynamic stochastic general equilibrium model with both financial frictions and endogenous growth. However, they do not introduce asset bubbles, and they study the model's local dynamics around the bubbleless steady state with a standard linearization method. As a result, they are unable to account for the growth slowdown after financial crises documented by Cerra and Saxena (2008), Blanchard, Cerutti, and Summers (2014), and Jorda, Schularick, and Taylor (2015).

Theoretically, one can generate growth slowdown (and acceleration) by introducing regimeswitching structural parameters if they generate the regime-dependent steady states. But it amounts to assuming that the economic structure changes in a particular way every time financial crisis occurs, an assumption for which we do not find convincing empirical support or a theoretical justification. ${ }^{8}$ Our paper therefore pursues an old idea that asset bubbles are a common element

\footnotetext{
${ }^{8}$ Guerron-Quintana and Jinnai (2019) document that there is no strong support for structural change in the financial market during or after the Great Recession; namely, many financial indicators temporarily deteriorated
} 
of many financial crises (Kindleberger (2001)), and their emergence and collapse are behind the growth acceleration and slowdown. ${ }^{9}$ More recently, Guerrieri and Uhlig (2016) in the Handbook of Macroeconomics emphasize that asset bubbles may play a key role to understand the observed boom-bust episodes.

\section{Model}

Our description of the model consists of regimes, firms, households, and endogenous productivity.

\subsection{Regimes}

Let $z_{t}$ denote a realization of the regime $z_{t} \in\{b, f\}$, where $b$ and $f$ denote the bubbly and fundamental regimes, respectively. Their defining characteristics are the existence or lack of bubbly assets, which are intrinsically useless. That is, bubbles contribute neither to production nor to households' utility directly. In the fundamental regime, there are no bubbly assets in the economy. When the regime switches to a bubbly one, $M$ units of bubbly assets are created and given to households in a lump-sum way. There is no creation of bubbly assets in other contingencies. Bubbly assets last without depreciation as long as the economy stays in the bubbly regime. We assume that they physically disappear suddenly and completely once the regime switches back to the fundamental one. ${ }^{10}$ We assume that $z_{t}$ follows a Markov process satisfying

$$
\operatorname{Pr}\left(z_{t}=f \mid z_{t-1}=f\right)=1-\sigma_{f}
$$

and

$$
\operatorname{Pr}\left(z_{t}=b \mid z_{t-1}=b\right)=1-\sigma_{b}
$$

\section{$3.2 \quad$ Firms}

Output is produced using capital and labor services denoted by $K S_{t}^{D}$ and $L_{t}^{D}$, respectively. The production function is

$$
Y_{t}=A_{t}\left(K S_{t}^{D}\right)^{\alpha}\left(L_{t}^{D}\right)^{1-\alpha}
$$

where $A_{t}$ is the technology level which agents in the economy take as given. Competitive firms choose $K S_{t}^{D}$ and $L_{t}^{D}$ to maximize profits defined as

$$
Y_{t}-r_{t} K S_{t}^{D}-w_{t} L_{t}^{D}
$$

after the bankruptcy of Lehman Brothers but have recovered.

${ }^{9}$ Hysteresis is another literature studying the growth slowdown. For example, Gali (2016) studies hysteresis in labor markets and the design of monetary policy. We view our work is as complementary.

${ }^{10}$ Alternatively, we can assume that the price of bubbly assets becomes zero. They are isomorphic. 
Here, $r_{t}$ is the rental price of capital and $w_{t}$ is the wage rate. First-order conditions are standard.

\subsection{Households}

The economy is populated by a continuum of households, with measure one. Each household has a unit measure of members who are identical at the beginning of each period. During the period, members are separated from each other, and each member receives a shock that determines her role in the period. A member will be an investor with probability $\pi \in[0,1]$ and will be a saver/worker with probability $1-\pi$. These shocks are i.i.d. among members and across time.

A period is divided into three stages. In the first stage, all members of a household are together and pool their assets, which are holdings of capital and, if it is the bubbly regime, holdings of bubbly assets. Aggregate shocks to exogenous state variables are realized. The household decides how intensively to use the capital it owns (i.e., the capacity utilization rate). Because all the members of the household are identical in this stage, the household head evenly divides the assets among the members. The household head also gives contingency plans to each member, describing the actions she should take if she becomes an investor or a saver/worker. The household's objective function is

$$
E_{0}\left[\sum_{t=0}^{\infty} \frac{\beta^{t}}{e^{b_{t}}}\left(\pi \frac{\left[c_{t}^{i}\right]^{1-\rho}-1}{1-\rho}+(1-\pi) \frac{\left[c_{t}^{s}\left(1-l_{t}\right)^{\eta}\right]^{1-\rho}-1}{1-\rho}\right)\right],
$$

where $c_{t}^{i}$ and $c_{t}^{s}$ are the consumption of investors and savers, respectively; $l_{t}$ is the labor supply by savers; and $b_{t}$ is a preference shock. After receiving instructions, members go to the market and they are separated from each other.

At the beginning of the second stage, each member receives the shock determining her role in the period. Markets open and competitive firms produce final goods. Compensation for productive factors is paid to their owners. A fraction $\delta\left(u_{t}\right)$ of capital depreciates, which is increasing and convex in the capacity utilization rate $u_{t}$ :

$$
\delta\left(u_{t}\right)=\delta_{0}+\frac{\delta_{1}}{1+\zeta} u_{t}^{1+\zeta}
$$

Investors seek financing to undertake investment projects. They have the technology to transform any amount of final goods into the same amount of new capital.

We introduce financial frictions following Kiyotaki and Moore (2019). Investors face a borrowing constraint due to their lack of commitment power. Namely, an investor who produces new capital cannot fully precommit to work with it even though her specific skill will be needed for capital to provide services. As a result, an investor can only issue new equity up to a fraction $\theta$ of her investment, implying

$$
\text { issue }_{t} \leq \theta i_{t}
$$

has to be satisfied, where $i_{t}$ denotes the amount of new capital produced by an investor and $i s s u e_{t}$ 
denotes the amount of equity issued by the same investor. The rest of the new capital must be held privately.

If equity finance does not raise enough funds, the investor seeks other ways to raise additional funds. The assets given to her in the first stage are useful for this purpose. Note that there are at most three kinds of assets in her portfolio. The first one is privately held capital that has been produced by members of the household that she belongs to but are unsold. The second one is equity issued by other households. In addition, if the economy is in the bubbly regime, there are bubbly assets.

Investors cannot sell privately held capital due to the lack of the commitment power we mentioned, but we assume that they can still use it as collateral to borrow short-term funds. Specifically, we assume that

$$
b_{t}^{i} \leq \tilde{\phi}_{t}\left(1-\delta\left(u_{t}\right)\right) n_{p, t}
$$

has to be satisfied, where $b_{t}^{i}$ is the amount of borrowing and $n_{p, t}$ is the amount of privately held capital the investor has at the beginning of the second stage. $\tilde{\phi}_{t}$ is a time-varying parameter. If $b_{t}^{i}$ is negative, the investor is a lender. As we explain momentarily, loans are repaid from the household's budget in the third stage of the period.

Our assumption about uncommitted capital is different from Kiyotaki and Moore (2019). That is, while we assume that investors use it as collateral to borrow funds, they assume that investors can sell it in the equity market up to a certain limit. A natural interpretation of their assumption will be that investors gain additional commitment power to the uncommitted old capital every period. Our model behaves identically under their assumption except for the stock market value, whose dynamics are more complicated under their assumption. Specifically, the equity-to-capital ratio has history dependence under their assumption, and therefore, if we add the stock market valuation as a variable of interest (as we do in the estimation section), we have to keep track of this ratio as an endogenous state variable. This is technically demanding for our study, because our model has regime switches. Our assumption that investors borrow short-term funds avoids this issue because it makes the equity-to-capital ratio constant at $\theta$, hence simplifying the analysis.

Regarding equity issued by other households, we make the same assumption as Kiyotaki and Moore (2019). That is, investors can sell only a fraction $\phi<1$ of her holdings of other households' equity before the investment opportunity disappears. In fact, we introduce transaction costs that are zero for the first fraction $\phi$ of equity sold, and then infinite. Let $n_{e, t}$ and $n_{e, t+1}^{i}$ denote the investor's holding of other households' equity at the beginning and at the end of the second stage, respectively. The resalability constraint is given by

$$
n_{e, t+1}^{i} \geq(1-\phi)\left(1-\delta\left(u_{t}\right)\right) n_{e, t}
$$

Selling bubbly assets in the bubbly regime is frinctionless. In the fundamental regime, there 
are neither spot nor future markets for bubbly assets. ${ }^{11}$ Without markets, no one can purchase bubbly assets, which is formally stated as follows: ${ }^{12}$

$$
\mathbf{1}_{\left\{z_{t}=f\right\}} \tilde{m}_{t+1}^{i}=\mathbf{1}_{\left\{z_{t}=f\right\}} \tilde{m}_{t+1}^{s}=0
$$

where $\mathbf{1}$ is an indicator function, and $\tilde{m}_{t+1}^{i}$ and $\tilde{m}_{t+1}^{s}$ are holdings of bubbly assets at the end of the second stage by investors and savers, respectively.

Our assumptions about asset tradings lead to the following investor's flow budget constraint:

$$
x_{t}^{i}+i_{t}+\underbrace{q_{t}\left(n_{e, t+1}^{i}-\left(1-\delta\left(u_{t}\right)\right) n_{e, t}\right)}_{\text {net equity purchase }}+\underbrace{\mathbf{1}_{\left\{z_{t}=b\right\}} \tilde{p}_{t}\left(\tilde{m}_{t+1}^{i}-\tilde{m}_{t}\right)}_{\text {net bubble purchase }}=\underbrace{u_{t} r_{t}\left(n_{e, t}+n_{p, t}\right)}_{\text {dividend }}+\underbrace{q_{t}\left(i s s u e_{t}\right)}_{\text {equity finance }}+\underbrace{b_{t}^{i}}_{\text {borrowing }},
$$

where $x_{t}^{i}$ is the amount of final goods the investor stores for use in the following stage, $\tilde{m}_{t}$ is the amount of bubbly assets given to the investor in the first stage, and $q_{t}$ and $\tilde{p}_{t}$ are the prices of equity and bubbly assets. The saver's flow budget constraint is similar to the investor's:

$$
x_{t}^{s}+q_{t}\left(n_{e, t+1}^{s}-\left(1-\delta\left(u_{t}\right)\right) n_{e, t}\right)+\mathbf{1}_{\left\{z_{t}=b\right\}} \tilde{p}_{t}\left(\tilde{m}_{t+1}^{s}-\tilde{m}_{t}\right)=u_{t} r_{t}\left(n_{e, t}+n_{p, t}\right)+w_{t} l_{t}+b_{t}^{s} .
$$

Here, $x_{t}^{s}, n_{e, t+1}^{s}, \tilde{m}_{t+1}^{s}$, and $b_{t}^{s}$ are saver's counterparts of $x_{t}^{i}, n_{e, t+1}^{i}, \tilde{m}_{t+1}^{i}$, and $b_{t}^{i}$ in equation (8). Savers also face the same financial constraints as investors. But we omit them because it can be shown that they do not bind in equilibrium.

In the third stage, the members of the household get together. The short-term loans are paid back from the household's budget. In a symmetric equilibrium,

$$
\pi b_{t}^{i}+(1-\pi) b_{t}^{s}=0
$$

holds. Then, consumption takes place. The household's resource constraint at this point in time is

$$
\pi x_{t}^{i}+(1-\pi) x_{t}^{s}=\pi c_{t}^{i}+(1-\pi) c_{t}^{s}
$$

After consumption, members' identities are forgotten. They start a new period as identical members. The household's portfolio at the beginning of period $t+1$ consists of holdings of other

\footnotetext{
${ }^{11}$ We also assume that agents cannot make a contract contingent on future bubbles; i.e., future bubbles cannot be used as collateral for loans in the current period.

${ }^{12}$ To justify this assumption, we could consider the following environment. Suppose that households need to pay transaction costs in order to investigate which assets bubbles are attached to in the future. If the transaction costs are sufficiently large, there will be no trading in the fundamental regime. Or suppose that there is a continuum of assets to which future bubbles can be attached. Households cannot know with certainty which assets bubbles can be attached to in the future. Under this setting, the probability that future bubbles can be attached to an asset is zero, and hence, the current price of that asset becomes zero. We thank Fernando Broner, Michihiro Kandori, and Alberto Martin for their discussion of these interpretations.
} 
households' equity

$$
n_{e, t+1}=\pi n_{e, t+1}^{i}+(1-\pi) n_{e, t+1}^{s},
$$

privately held capital

$$
n_{p, t+1}=\left(1-\delta\left(u_{t}\right)\right) n_{p, t}+\pi\left(i_{t}-i s s u e_{t}\right)
$$

and bubbly assets

$$
\tilde{m}_{t+1}=\pi \tilde{m}_{t+1}^{i}+(1-\pi) \tilde{m}_{t+1}^{s}+\mathbf{1}_{\left\{z_{t}=f, z_{t+1}=b\right\}} M
$$

The household's problem is summarized as follows. It chooses a sequence of $u_{t}, x_{t}^{i}, c_{t}^{i}, i_{t}, n_{e, t+1}^{i}$, $\tilde{m}_{t+1}^{i}, b_{t}^{i}$, issue $_{t}, x_{t}^{s}, c_{t}^{s}, l_{t}, n_{e, t+1}^{s}, \tilde{m}_{t+1}^{s}$, and $b_{t}^{s}$ to maximize the utility function (3) subject to the constraints (4), (5), (6), (7), (8), (9), (10), (11), (12), and (13). The initial portfolio $\left\{n_{e, 0}, n_{p, 0}, \tilde{m}_{0}\right\}$ is given. Except for $b_{t}^{i}$ and $b_{t}^{s}$, the control variables must be non-negative.

Because this problem is hard to analyze in a general form, we make a simplifying assumption following Kiyotaki and Moore (2019) and Del Negro, Eggertsson, Ferrero, and Kiyotaki (2017). Specifically, we assume that $\tilde{\phi}_{t}=\phi q_{t}$ always holds. It can be justified in several ways. For example, if lenders can convert a unit of uncommitted capital into $\phi$ units of general capital that can be easily used by anyone and hence sold in the equity market, $\tilde{\phi}_{t}=\phi q_{t}$ holds. This assumption simplifies the analysis because the other households' equity and the household's privately held capital become perfect substitutes for the household, paying the same return per unit and providing the same amount of liquidity per period. The household no longer has to keep track of these two assets separately, but the total capital owned by the household, $n_{t} \equiv n_{e, t}+n_{p, t}$, becomes the relevant state variable for the household. $q_{t}$ is not only the equity price but also the household's subjective valuation of privately held capital. However, the distinction between $n_{e, t}$ and $n_{p, t}$ is still important for the measurement of the stock market value.

\subsection{Endogenous Growth}

We assume that the technology level $A_{t}$ is endogenous:

$$
A_{t}=\bar{A}\left(K_{t}\right)^{1-\alpha} e^{a_{t}}
$$

$a_{t}$ is an exogenous productivity shock and $\bar{A}$ is a scale parameter. Following Arrow (1962), Sheshinski (1967), and Romer (1986), we interpret the dependency of $A_{t}$ on $K_{t}$ as learning-bydoing; namely, knowledge is a by-product of investment, and in addition, it is a public good that anyone can access at zero cost. With it, the long-run tendency for capital to experience diminishing returns is eliminated. 


\subsection{Market Clearing}

Competitive equilibrium is defined in a standard way; all agents optimize given prices; the market clearing conditions are satisfied for equity

$$
n_{e, t+1}=\left(1-\delta\left(u_{t}\right)\right) n_{e, t}+\pi\left(\text { issue }_{t}\right),
$$

labor services

$$
L_{t}^{D}=(1-\pi) l_{t},
$$

capital services

$$
K S_{t}^{D}=u_{t} K_{t}
$$

and final goods

$$
\pi c_{t}^{i}+(1-\pi) c_{t}^{s}+\pi i_{t}=Y_{t}
$$

for all $t$. If the economy is in the bubbly regime $\left(z_{t}=b\right)$, the market clearing condition for the bubbly assets

$$
\pi \tilde{m}_{t+1}^{i}+(1-\pi) \tilde{m}_{t+1}^{s}=M
$$

is also satisfied. In addition, the consistency condition

$$
n_{e, t}+n_{p, t}=K_{t}
$$

is satisfied for all $t$. Because the constraint (7) implies that $\pi \tilde{m}_{t+1}^{i}+(1-\pi) \tilde{m}_{t+1}^{s}=0$ holds if the economy is in the fundamental regime $\left(z_{t}=f\right)$, we have

$$
\pi \tilde{m}_{t+1}^{i}+(1-\pi) \tilde{m}_{t+1}^{s}=\mathbf{1}_{\left\{z_{t}=b\right\}} M
$$

for all $t$. The law of motion for aggregate capital stock is

$$
K_{t+1}=\left(1-\delta\left(u_{t}\right)\right) K_{t}+\pi i_{t},
$$

which is implied by (12), (14), and (15).

\subsection{Solving the Household's Problem}

It is convenient to solve the household's problem in two cases, depending on the tightness of the financial constraints. 


\subsubsection{When Financial Constraints Are Loose}

We can guess and verify that the equilibrium price of capital is equal to one if the financial constraints are sufficiently loose (i.e., $\theta$ and $\phi$ are sufficiently large). We can also show that the equilibrium price of bubbly assets is zero in this case. The constraints of the household's optimization problem are summarized in a single equation:

$$
\pi c_{t}^{i}+(1-\pi) c_{t}^{s}+n_{t+1}=\left[u_{t} r_{t}+\left(1-\delta\left(u_{t}\right)\right)\right] n_{t}+w_{t}(1-\pi) l_{t}
$$

where $n_{t}$ is the total amount of capital owned by the household, $n_{t}=n_{e, t}+n_{p, t}$. The first-order conditions are

$$
\begin{gathered}
\left(c_{t}^{i}\right)^{-\rho}=\left(c_{t}^{s}\right)^{-\rho}\left(1-l_{t}\right)^{\eta(1-\rho)}, \\
\eta \frac{c_{t}^{s}}{1-l_{t}}=w_{t} \\
r_{t}-\delta^{\prime}\left(u_{t}\right)=0
\end{gathered}
$$

and

$$
1=E_{t}\left[\frac{\beta}{e^{b_{t+1}-b_{t}}}\left(\frac{c_{t}^{i}}{c_{t+1}^{i}}\right)^{\rho}\left(u_{t+1} r_{t+1}+1-\delta\left(u_{t+1}\right)\right)\right] .
$$

The first equation states that the marginal utility from consumption has to be equalized across members of the household. The second equation states that the marginal rate of substitution between leisure and consumption has to be equal to the wage. The third equation states that the marginal benefit of raising the capacity utilization rate has to be equal to its opportunity cost, which is the amount of depreciated capital at the margin. The last equation is the Euler equation.

\subsubsection{When Financial Constraints Are Tight}

In the second case, both $\theta$ and $\phi$ are small, and inequality constraints (4), (5), and (6) bind in equilibrium. The price of capital exceeds one in this case. ${ }^{13}$ This is so because capital provides not only capital services but also liquidity to its owners. Moreover, $1<q_{t}<1 / \theta$ holds in equilibrium, implying that producing new capital is profitable but investment cannot be made without down payments. In addition, we can show that $\mathbf{1}_{\left\{z_{t}=b\right\}} \tilde{p}_{t} \tilde{m}_{t+1}^{i}=0$ always holds. ${ }^{14}$

\footnotetext{
${ }^{13}$ The three inequality constraints (4), (5), and (6) bind simultaneously if $q_{t}>1$. If (4) is not binding, households can increase their utility without violating any constraints or affecting their portfolio at the end of the period by increasing both $i_{t}$ and issue $e_{t}$ by $\Delta>0$, and increasing both $x_{t}^{i}$ and $c_{t}^{i}$ by $\left(q_{t}-1\right) \Delta$, which is a contradiction to the household's optimization. If (5) is not binding, households can increase their utility without violating any constraints or affecting $n_{t+1}$ by increasing both $i_{t}$ and $b_{t}^{i}$ by $\Delta$, decreasing $n_{e, t+1}^{s}$ by $(\pi /(1-\pi)) \Delta$, increasing $x_{t}^{s}$ by $(\pi /(1-\pi)) q_{t} \Delta$, and increasing $c_{t}^{i}$ by $\left(q_{t}-1\right) \Delta$. If (6) is not binding, households can increase their utility without violating any constraints or affecting $n_{t+1}$ by increasing $i_{t}$ by $\Delta$, decreasing $n_{e, t+1}^{i}$ by $\left(1 / q_{t}\right) \Delta$, decreasing $n_{e, t+1}^{s}$ by $(\pi /(1-\pi))\left(\left(q_{t}-1\right) / q_{t}\right) \Delta$, and increasing both $x_{t}^{s}$ and $c_{t}^{s}$ by $(\pi /(1-\pi))\left(q_{t}-1\right) \Delta$.

${ }^{14}$ Suppose the opposite, i.e., $\mathbf{1}_{\left\{z_{t}=b\right\}} \tilde{p}_{t} \tilde{m}_{t+1}^{i}>0$ holds in period $t$. Then, households can relax (6) without violating any constraints or affecting their portfolio at the end of the period by decreasing $\tilde{m}_{t+1}^{i}$ by $\Delta>0$, increasing $\tilde{m}_{t+1}^{s}$ by $(\pi /(1-\pi)) \Delta$, increasing $n_{e, t+1}^{i}$ by $\tilde{p}_{t} \Delta / q_{t}$, and decreasing $n_{e, t+1}^{s}$ by $(\pi /(1-\pi))\left(\tilde{p}_{t} / q_{t}\right) \Delta$. This is a contradiction
} 
Combining (8), (9), (10), (11), (12), and $\mathbf{1}_{\left\{z_{t}=b\right\}} \tilde{p}_{t} \tilde{m}_{t+1}^{i}=0$, we obtain the budget constraint at the household level:

$$
\begin{aligned}
& \pi c_{t}^{i}+(1-\pi) c_{t}^{s}+\pi i_{t}+q_{t}\left[n_{t+1}-\left(1-\delta\left(u_{t}\right)\right) n_{t}\right]+\mathbf{1}_{\left\{z_{t}=b\right\}} \tilde{p}_{t}\left((1-\pi) \tilde{m}_{t+1}^{s}-\tilde{m}_{t}\right) \\
= & u_{t} r_{t} n_{t}+\pi q_{t} i_{t}+(1-\pi) w_{t} l_{t} .
\end{aligned}
$$

Because (4), (5), and (6) hold with equality, and in addition $\mathbf{1}_{\left\{z_{t}=b\right\}} \tilde{p}_{t} \tilde{m}_{t+1}^{i}=0$ holds, we can rewrite the investor's budget constraint (8) as follows:

$$
\left(1-\theta q_{t}\right) i_{t}=\left[u_{t} r_{t}+\phi q_{t}\left(1-\delta\left(u_{t}\right)\right)\right] n_{t}+\mathbf{1}_{\left\{z_{t}=b\right\}} \tilde{p}_{t} \tilde{m}_{t}
$$

Substituting (17) into (16), we find

$$
\begin{aligned}
& \pi c_{t}^{i}+(1-\pi) c_{t}^{s}+q_{t} n_{t+1}+\mathbf{1}_{\left\{z_{t}=b\right\}} \tilde{p}_{t}(1-\pi) \tilde{m}_{t+1}^{s} \\
= & {\left[u_{t} r_{t}+\left(1-\delta\left(u_{t}\right)\right) q_{t}\right] n_{t}+\pi \lambda_{t}\left(u_{t} r_{t}+\phi q_{t}\left(1-\delta\left(u_{t}\right)\right)\right) n_{t} } \\
& +\mathbf{1}_{\left\{z_{t}=b\right\}} \tilde{p}_{t}\left(1+\pi \lambda_{t}\right) \tilde{m}_{t}+(1-\pi) w_{t} l_{t},
\end{aligned}
$$

where

$$
\lambda_{t} \equiv \frac{q_{t}-1}{1-\theta q_{t}} .
$$

$\lambda_{t}$ measures how much value an investor can create from a unit of liquidity. The reason is the following. An investor can create $1 /\left(1-\theta q_{t}\right)$ units of capital from a unit of liquidity, which is the reciprocal of the marginal down payment. A fraction $\theta$ of the investment is equity financed, and the rest is added to the investor's portfolio, which is worth $(1-\theta) q_{t} /\left(1-\theta q_{t}\right)$. Finally, substracting the costs of the investment from it, we find

$$
\frac{(1-\theta) q_{t}}{1-\theta q_{t}}-1=\frac{q_{t}-1}{1-\theta q_{t}}=\lambda_{t}
$$

Hence, $\lambda_{t}$ is the marginal revenue from investment with leverage.

The household's problem is now simplified. It chooses a sequence of $u_{t}, c_{t}^{i}, c_{t}^{s}, l_{t}, n_{t+1}$, and $\tilde{m}_{t+1}^{s}$ to maximize the utility (3) subject to the budget constraint (18), the law of motion of bubbly assets

$$
\tilde{m}_{t+1}=(1-\pi) \tilde{m}_{t+1}^{s}+\mathbf{1}_{\left\{z_{t}=f, z_{t+1}=b\right\}} M
$$

and the absence of the bubbly-asset market in the fundamental regime

$$
\mathbf{1}_{\left\{z_{t}=f\right\}} \tilde{m}_{t+1}^{s}=0
$$

to the household's optimization because they can increase utility if (6) is not binding. 
The first-order conditions are

$$
\begin{gathered}
\left(c_{t}^{i}\right)^{-\rho}=\left(c_{t}^{s}\right)^{-\rho}\left(1-l_{t}\right)^{\eta(1-\rho)} \\
\eta \frac{c_{t}^{s}}{1-l_{t}}=w_{t} \\
q_{t}=E_{t}\left[\frac{\beta}{e^{b_{t+1}-b_{t}}}\left(\frac{c_{t}^{i}}{c_{t+1}^{i}}\right)^{\rho}\left(u_{t+1} r_{t+1}+\left(1-\delta\left(u_{t+1}\right)\right) q_{t+1}+\pi \lambda_{t+1}\left(u_{t+1} r_{t+1}+\phi q_{t+1}\left(1-\delta\left(u_{t+1}\right)\right)\right)\right)\right],
\end{gathered}
$$

and

$$
\mathbf{1}_{\left\{z_{t}=b\right\}} \tilde{p}_{t}=\mathbf{1}_{\left\{z_{t}=b\right\}} E_{t}\left[\frac{\beta}{e^{b_{t+1}-b_{t}}}\left(\frac{c_{t}^{i}}{c_{t+1}^{i}}\right)^{\rho}\left(1+\pi \lambda_{t+1}\right) \tilde{p}_{t+1} \mathbf{1}_{\left\{z_{t+1}=b\right\}}\right] .
$$

The first two equations are the same as in the previous section, but the other equations are either different or new. The third equation is the optimality condition for the capacity utilization rate, and the fourth equation is the Euler equation for capital. The price of capital $q_{t}$ appears in the second term in (19) because the opportunity cost of raising the capacity utilization rate is the value of depreciated capital at the margin. $\lambda_{t}$ appears in the third term in (19) because the household head can provide additional liquidity to investors by raising the capacity utilization rate. $\lambda_{t}$ appears in the right-hand side of (20) because capital is not only a production factor but also a means of providing liquidity to investors. Capital is valued based on both of these services.

Equation (21) is the Euler equation for the bubbly asset, and this is the key equation in our model. Two observations are worth noting. First, bubbles exist in period $t$, by which we mean that the left-hand side of the equation, $\mathbf{1}_{\left\{z_{t}=b\right\}} \tilde{p}_{t}$, is strictly positive, only if there is a chance that the bubbly assets in period $t$ will be traded at a strictly positive value in the next period. In other words, it is the resalability of bubbly assets in the future that justifies their positive prices today. Second, the parameter $\phi$ is absent in the bubble's Euler equation. Bubbly assets provide more liquidity than capital, and with this advantage, savers may find the two assets indifferent at the margin even though bubbly assets are intrinsically useless.

Because $\mathbf{1}_{\left\{z_{t}=b\right\}} \tilde{m}_{t}=\mathbf{1}_{\left\{z_{t}=b\right\}} M$ holds in equilibrium, equation (17) can be rewritten as follows:

$$
i_{t}=\frac{\left[u_{t} r_{t}+\phi q_{t}\left(1-\delta\left(u_{t}\right)\right)\right] n_{t}+\tilde{p}_{t} \mathbf{1}_{\left\{z_{t}=b\right\}} M}{1-\theta q_{t}} .
$$

The term $\tilde{p}_{t} \mathbf{1}_{\left\{z_{t}=b\right\}} M$ is positive if and only if asset price bubbles exist $\left(\tilde{p}_{t} \mathbf{1}_{\left\{z_{t}=b\right\}}>0\right)$. This is the crowding-in effect of realized bubbles. Namely, they provide liquidity to investors, through which they increase gross investment. In the appendix, we discuss that equation (22) plays a crucial role in determining whether bubbles are sustainable or not.

We can discuss the key insight of our paper now, i.e., the crowding-out effect of future bubbles. 
Substituting the budget constraint (18) forward, we derive an intertemporal budget constraint:

$$
\begin{aligned}
& \pi c_{0}^{i}+(1-\pi) c_{0}^{s}+E_{0}\left[\sum_{t=1}^{\infty} \frac{1}{R_{n, 1} \cdots R_{n, t}}\left(\pi c_{t}^{i}+(1-\pi) c_{t}^{s}\right)\right] \\
= & \left(u_{0} r_{0}+\left[1-\delta\left(u_{0}\right)\right] q_{0}+\pi \lambda_{0}\left[u_{0} r_{0}+\phi q_{0}\left(1-\delta\left(u_{0}\right)\right)\right]\right) n_{0} \\
& +(1-\pi)\left(w_{0} l_{0}+E_{0}\left[\sum_{t=1}^{\infty} \frac{1}{R_{n, 1} \cdots R_{n, t}} w_{t} l_{t}\right]\right) \\
& +\pi\left(\lambda_{0} \tilde{p}_{0} \mathbf{1}_{\left\{z_{0}=b\right\}} M+E_{0}\left[\sum_{t=1}^{\infty} \frac{1}{R_{1, t} \cdots R_{n, t}} \lambda_{t} \tilde{p}_{t} \mathbf{1}_{\left\{z_{t}=b\right\}} M\right]\right),
\end{aligned}
$$

where $R_{n, t}$ denotes the private return to capital, which is defined as

$$
R_{n, t} \equiv \frac{u_{t} r_{t}+\left(1-\delta\left(u_{t}\right)\right) q_{t}+\pi \lambda_{t}\left(u_{t} r_{t}+\phi q_{t}\left(1-\delta\left(u_{t}\right)\right)\right)}{q_{t-1}} .
$$

The left-hand side of (23) is the present value of current and future consumption. The first term in the right-hand side is the value of capital. The second term is the present value of current and future labor income. Finally, the third term is the present value of current and future liquidity provided by bubbly assets. If this term is positive, it relaxes the budget constraint, increasing consumption, decreasing labor supply (via wealth effects), and hence leaving fewer resources for investment. This is the crowding-out effect of bubbles in our model.

Importantly, the third term has both current and future bubbles. Because current bubbles appear in both (22) and (23), current bubbles have both the crowding-in effect and the crowdingout effect. Their overall impact on investment and growth is therefore uncertain but is ultimately a quantitative question. Future bubbles are different; they appear only in (23), and therefore, they have the crowding-out effect alone. If bubbles are expected, they reduce investment and growth, and this effect exists in both the fundamental and bubbly regimes. We discuss this implication in detail in the following sections.

\section{Calibration}

As discussed above, recurrent bubbles in our model have both the crowding-in and the crowdingout effects of realized bubbles as well as the crowding-out effect of future bubbles. To quantify their impact on growth and welfare, we turn to a quantitative analysis. Table 1 summarizes the parameter values used in the rest of the paper. We set the discount factor at $\beta=0.99$, the inverse of the intertemporal elasticity of substitution at $\rho=1$, the capital share at $\alpha=0.33$, and the elasticity of $\delta^{\prime}\left(u_{t}\right)$ at $\zeta=0.33$, following Comin and Gertler (2006). The probability of having an investment opportunity is set at $\pi=0.06$, following Shi (2015).

The rest of the parameters are calibrated in the model. We assume that if the financial 


\begin{tabular}{ccc}
\hline Parameter & Value & Calibration Target \\
\hline$\beta$ & 0.99 & Exogenously Chosen \\
$\rho$ & 1 & Exogenously Chosen \\
$\zeta$ & 0.33 & Exogenously Chosen \\
$\alpha$ & 0.33 & Capital Share $=0.33$ \\
$\pi$ & 0.06 & Shi $(2015)$ \\
$\delta_{0}$ & 0.001 & Frictionless Growth $g^{4}=1.02$ \\
$\delta_{1} u^{1+\zeta}$ & 0.065 & Frictionless Depreciation $\delta(u)=0.05$ \\
$\eta$ & 2.67 & Frictionless Hours $l=0.27$ \\
$\bar{A} u^{\alpha}$ & 0.49 & Equilibrium Condition \\
$u$ & 1 & Normalization \\
\hline
\end{tabular}

Table 1: Parameters and Calibration Targets

constraints are sufficiently loose and therefore do not bind, the growth rate of the economy would be $2 \%$ per annum, the hours worked would be $27 \%$ of the available time, and the depreciation rate would be $5 \%$ per quarter along the balanced growth path. We then solve for the three parameters $\delta_{0}, \delta_{1} u^{1+\zeta}$, and $\eta$ jointly. We find the value of $\bar{A} u^{\alpha}$ from the equilibrium condition. We set $u=1$, which is just a normalization.

One may find that the target depreciation rate (5\% per quarter) is high, but remember that this is the depreciation rate in an extreme situation in which the financial constraints never bind. Previous studies in the literature assume that the financial constraints are relevant. If we follow Kiyotaki and Moore (2019) and set them at $\theta=\phi=0.19$ in our calibrated model, the implied depreciation rate is $2.4 \%$ per quarter. However, we are agnostic about the values of $\theta$ and $\phi$ at this point. We show comparative statics with respect to these parameters in the following section.

\section{Comparative Statics}

In this section, we discuss the impact of bubbles on growth and then on welfare.

\subsection{Growth in Fundamental Equilibrium}

The blue line in Figure 1 shows how the financial frictions influence economic growth in a bubbleless equilibrium. We assume that both productivity and preference shocks are constant at $a_{t}=b_{t}=0$ for all $t$ in this exercise. We set $\theta=\phi$ and display them along the horizontal axis. The left side of the figure therefore corresponds to a situation in which investors struggle to obtain funds. We interpret it as an economy whose financial system is underdeveloped. By the same token, we interpret that the right side of the figure corresponds to an economy whose financial system is developed. Although $\theta=\phi$ is imposed in this section, our main results are robust to more general situations. 
For now, we focus on an equilibrium in which bubbly assets are never traded at a positive price. We call it the fundamental equilibrium, because it is essentially the same as the economy always being in the fundamental regime. The flat part of the line on the right part of the figure shows that economic growth is constant once the level of financial development reaches a certain threshold. Beyond this point, the financial constraints do not bind. On the left part, the growth rate is influenced by the level of financial development. Interestingly, it shows an inverted U shape, implying that neither a too underdeveloped nor a too advanced financial system is beneficial for growth, but growth is maximized in an intermediate stage of financial development.

To understand non-monotonicity, it is important to distinguish net investment from gross. In our economy, capital depreciation depends on the capacity utilization rate, which in turn depends on the price of capital because households care about the value of depreciated capital. ${ }^{15}$ The price of capital tends to be low in an economy with an advanced financial system (blue line in the third panel in the right column of Figure 2), ${ }^{16}$ and therefore, a high utilization rate is chosen there. A resulting high depreciation rate slows down capital accumulation by reducing net investment, creating a parameter region in which financial development does not necessarily enhance growth. ${ }^{17}$

\subsection{Growth with Stochastic Bubble}

Now let us analyze the impact of bubbles on economic growth. We first look at the so-called stochastic bubble. Let us assume that bubbles exist at the beginning of history, i.e., $\mathbf{1}_{\left\{z_{0}=b\right\}} \tilde{p}_{0}>0$. This initial bubble, however, bursts with a positive probability, triggered by the regime switch. After the bursting, there is no re-emergence of bubbles, and neither are bubbles expected. Specifically, we set $\sigma_{f}=0$, and hence, the fundamental regime is an absorbing state. This kind of bubble, bursting stochastically after which the economy is permanently bubbleless, is studied in the pioneering work of Weil (1987).

We assume that the probability of the bursting is $1.5 \%$ per quarter, meaning that the expected duration of the bubble is about 16.5 years. This duration is not unusual in the literature; for example, Hirano and Yanagawa (2017) analyze stochastic bubbles with an average duration varying

\footnotetext{
${ }^{15}$ If capital is cheap, households are less reluctant to raise the utilization rate because the opportunity cost is low.

${ }^{16}$ The price of capital is downward sloping for the following reason. In an economy with a sufficiently developed financial system, the price of capital is one. Remember that capital is nothing but a production factor there. However, if the financial system is less developed, the price of capital exceeds one. This is so because capital is now a production factor as well as a source of liquidity. Because the value of liquidity is high if it is limited, the price of capital is higher in an economy with a less developed financial system.

${ }^{17}$ The effect of financial development on gross investment becomes weaker as the financial system develops (blue line in the second panel in the left column of Figure 2). The reason is the following. Remember that an investor can sell a fraction $\theta$ of newly produced capital at price $q$; can borrow $\phi \times q$ units of goods with a unit of old capital used as collateral; and can resell a fraction $\phi$ of the other households' equity at price $q$. In all of these activities, the amount of liquidity an investor can obtain from a unit of capital is either $\theta \times q$ or $\phi \times q$, and hence, it depends on $q$ multiplicatively. This means that if $q$ is high, even a small increase in $\theta$ or $\phi$ delivers a sizable amount of liquidity to an investor, and this is the case in an economy with an underdeveloped financial system. The opposite is true in an economy with a developed financial system.
} 


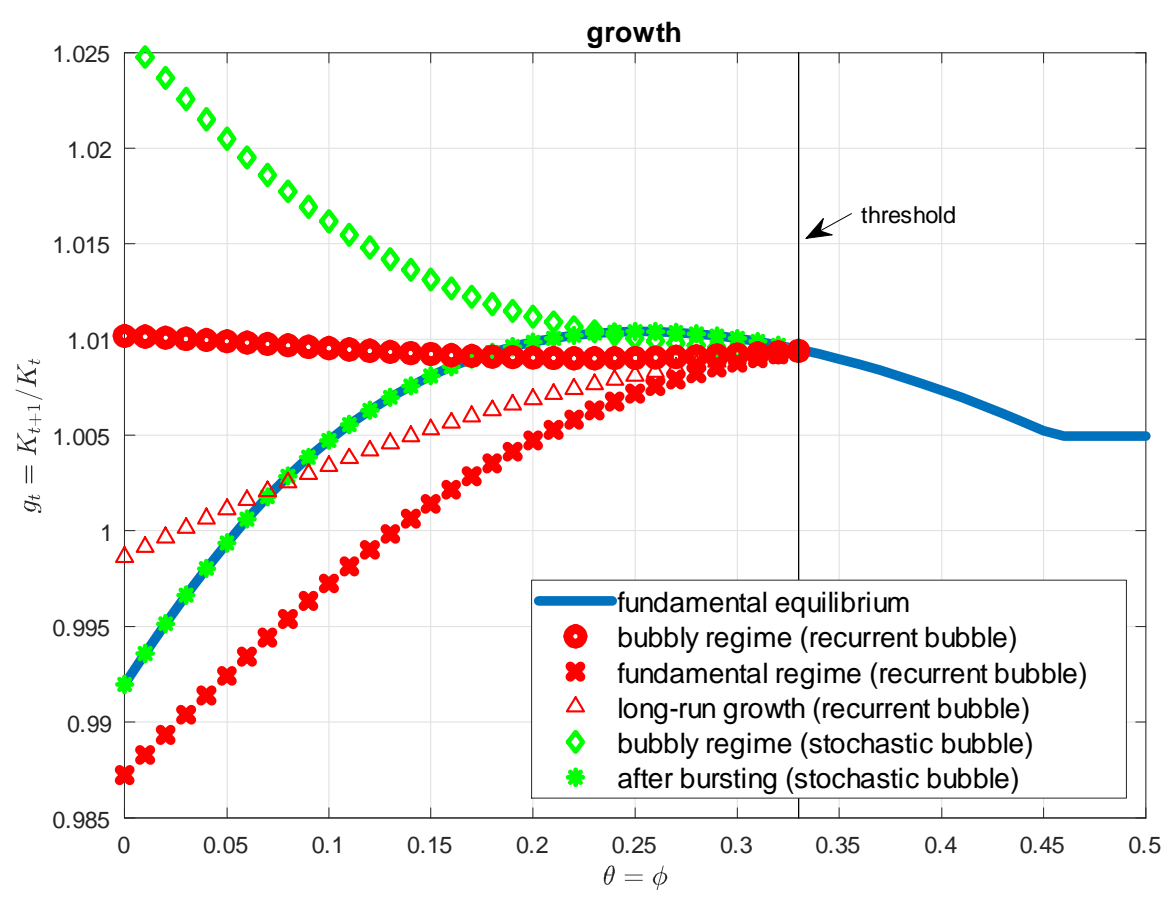

Figure 1: Financial Frictions and Economic Growth

from 12.5 to 100 years. Long duration has been assumed in the literature because bubbles are not supported as an equilibrium outcome if they are too short-lived. ${ }^{18}$ The intuition is simple; no one buys bubbles if one knows that their collapse is just around the corner. Instead, buyers must believe that bubbles are reasonably durable, and it is ultimately these buyers' beliefs that we model as the relevant probabilities.

The green diamonds and asterisks in Figure 1 show the growth rate of capital, $g_{t}=K_{t+1} / K_{t}$, in the stochastic-bubble equilibrium. There are two plots because it is regime-dependent. The bubbly equilibrium does not exist if the level of financial development is sufficiently high. The vertical line in the figure shows the threshold value for the existence of bubbles $(\theta=\phi \approx 0.23)$.

Capital accumulation is generally faster in the initial bubbly regime than after the bursting. Economic growth follows a similar path; it is generally faster in the initial bubbly regime than after the bursting too, because in the current environment, the speed of capital accumulation and the speed of economic growth are identical except for the period in which the regime switch occurs. The intertemporal substitution, or the inter-regime substitution more precisely, is important. As shown in the second row in Figure 2, households work harder and invest more in the bubbly regime than in the fundamental one. The bubbly regime is a favorable time for investment, and

\footnotetext{
${ }^{18}$ If the bursting probability is too high, bubbles must offer extremely high returns to compensate for the risk; otherwise, they won't be demanded. This means that if the bursting probability is too high, bubbles must grow at an excessive pace as long as they last. But then, with a positive probability, they reach a point at which no one can afford to buy them. This is not supported as an equilibrium outcome (Weil (1987)).
} 

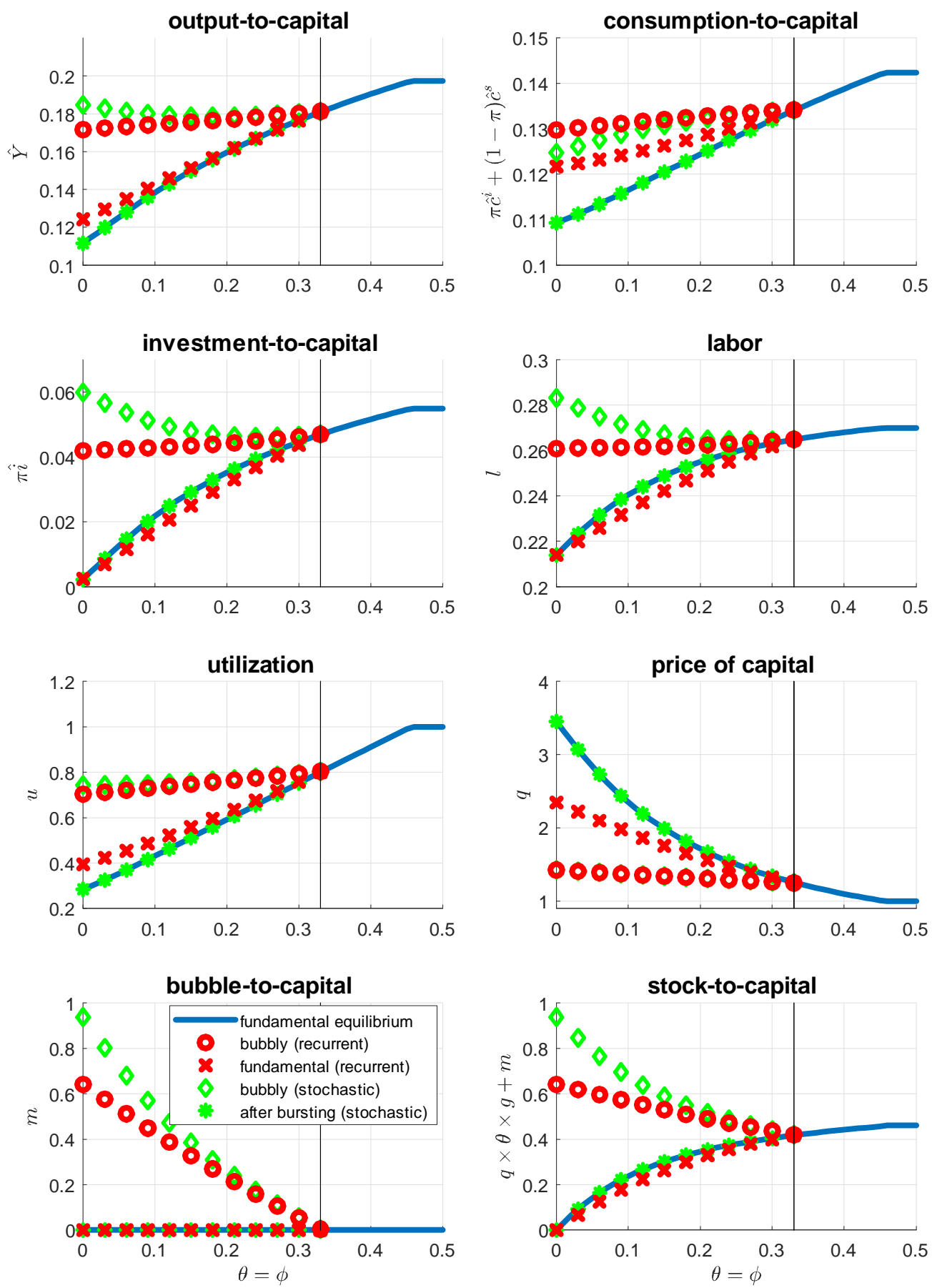

Figure 2: Financial Frictions and Macroeconomic Variables 
households, recognizing it, optimally allocate both time and resources not only across time but also across regimes. This is the crowding-in effect of realized bubbles. ${ }^{19}$

The inter-regime substitution can cause a severe recession when the bubble bursts. Suppose that the bubble collapses in period $T>0$. GDP growth in period $T$ is given by

$$
\frac{Y_{T}}{Y_{T-1}}=\frac{Y_{T} / K_{T}}{Y_{T-1} / K_{T-1}} \frac{K_{T}}{K_{T-1}}=\frac{\hat{Y}_{f}}{\hat{Y}_{b}} g_{b},
$$

where $\hat{Y}_{f}$ and $\hat{Y}_{b}$ are the level of output relative to capital stock in the fundamental and the bubbly regime, respectively, and they are plotted in the first panel in the left column in Figure 2. $g_{b}$ is the growth rate of capital in the bubbly regime, plotted in Figure 1. Because $\hat{Y}_{b}$ is larger than $\hat{Y}_{f}$, GDP growth can plunge when the bubble bursts. This is the short-run impact of the bursting bubble on GDP growth. It is clear from Figure 2 that the short-run impact is larger in an economy with an underdeveloped financial system.

The fourth panel in the left column in Figure 2 plots the size of the bubble relative to capital stock, i.e., $m_{t} \equiv \tilde{p}_{t} \mathbf{1}_{\left\{z_{t}=b\right\}} M / K_{t}$. It is regime-dependent, satisfying $m_{f}=0$ and $m_{b}>0$. The size of the stochastic bubble is larger in an economy with an underdeveloped financial system. When we compare $m_{b}$ to the output level $\hat{Y}_{b}$ plotted in the first panel in the left column, we see that the size of the bubble even exceeds annual GDP $\left(\approx 4 \times \hat{Y}_{b}\right)$ if the level of financial development is extremely low. The fourth panel in the right column plots the stock market value relative to capital stock. Our definition of the stock market value is the total (tradable) asset value:

$$
\text { stock } k_{t} \equiv q_{t} n_{e, t+1}+\tilde{p}_{t} \mathbf{1}_{\left\{z_{t}=b\right\}} M \text {. }
$$

We assume that $n_{e, 0}=\theta K_{0}$ holds in period 0 . Then, $n_{e, t+1}=\theta K_{t+1}$ holds for $t \geq 0 .{ }^{20}$ We see in the figure that the stock market value is larger in the bubbly regime than in the fundamental regime. This means that the stock market value drops when the bubble bursts. This is an important observation for our empirical investigation discussed later.

\subsection{Growth with Recurrent Bubble}

To analyze recurrent bubbles, we assume that the probabilities of regime switches are $1.5 \%$ per quarter in both directions, but the results are robust to other choices. Furthermore, we require that the price of bubbly assets to always be positive whenever they exist $\left(\tilde{p}_{t}>0\right.$ if $\left.z_{t}=b\right)$. We call this equilibrium the recurrent-bubble equilibrium. As in the stochastic-bubble one, the

\footnotetext{
${ }^{19}$ As we discuss in the previous section, there is a crowding-out effect of realized bubbles too. The fact that the growth rate in the initial bubbly regime is generally higher than the growth rate after the bursting means that the crowding-in effect of the stochastic bubble dominates the crowding-out effect of the stochastic bubble.

${ }^{20}$ If $q_{t}>1$ holds for all $t \geq 0$, issue $e_{t}=\theta i_{t}$ holds for all $t \geq 0$. If $q_{t}=1$ holds, any level of equity issuance between 0 and $\theta i_{t}$ is optimal for investors. We assume that they choose $i s s u e_{t}=\theta i_{t}$.
} 
recurrent-bubble equilibrium exists only if the level of financial development is relatively low, and the growth rate of capital and the growth rate of GDP are identical except for the period in which the regime switch occurs.

The red circles and crosses in Figure 1 show the regime-dependent capital growth in the recurrent-bubble equilibrium. Clearly, it is higher in the bubbly regime (red circle) than in the fundamental regime (red cross). This inter-regime growth differential is the result of the crowdingin effect of realized bubbles we discussed in the previous section. When we compare the growth rates across equilibria, we see that growth rates in the recurrent-bubble equilibrium are generally lower than those in the stochastic-bubble equilibrium, conditional on being in the same regime (red circle versus green diamond for the bubbly regime, and red cross versus green asterisk for the fundamental regime). This inter-equilibrium growth differential is the result of the crowding-out effect of future bubbles, which we will discuss momentarily.

In the recurrent-bubble equilibrium, growth stagnation occurs. Namely, the economic growth in the fundamental regime (red cross) is consistently lower than that in the fundamental equilibrium (blue line). This result is interesting for at least two reasons. First, the difference is observed even though the environments are objectively identical; in both cases, no asset price bubbles exist at the time of the comparison. Second, we do not see this property for the stochastic-bubble equilibrium; namely, green asterisks are on top of the blue line.

Growth stagnation occurs because of the crowding-out effect of future bubbles. As we see in Figure 2, people consume more, work less (spend more time on leisure), and invest less in the fundamental regime of the recurrent-bubble equilibrium than in the fundamental equilibrium. They understand that future bubbles will make them richer, and this expectation makes people lazy now, loosely speaking. ${ }^{21}$

Growth stagnation has an important implication for long-run (unconditional) growth. The red triangles in Figure 1 show the long-run capital growth in the recurrent-bubble equilibrium, which is identical to the long-run economic growth in the same equilibrium. ${ }^{22}$ In economies with relatively developed financial systems, the long-run growth in the recurrent-bubble equilibrium (red triangle) can be slower than the long-run growth in the fundamental equilibrium (blue line). This result is a consequence of the growth stagnation. Note that in the stochastic-bubble equilibrium, the longrun growth calculated in the same manner is identical to the long-run growth in the fundamental equilibrium.

\footnotetext{
${ }^{21}$ The capacity utilization rate reduces net investment too. Namely, as shown in Figure 2, the price of capital is low if people expect bubbles to emerge in the future because bubbles provide liquidity to the economy, diluting the value of capital as a source of liquidity. The low price of capital leads to a high capacity utilization rate, slowing down the speed of capital accumulation as well as economic growth.

${ }^{22}$ It is given by

$$
\bar{g}=g_{f r}^{\frac{\sigma_{b}}{\sigma_{f}+\sigma_{b}}} g_{b r}^{\frac{\sigma_{f}}{\sigma_{f}+\sigma_{b}}}
$$

where $g_{b}$ and $g_{f}$ denote capital growth in the bubbly and fundamental regimes, respectively. The short-run impacts of the emergence and the collapse of bubbles on GDP growth perfectly offset each other because they are symmetric.
} 
In economies with underdeveloped financial systems, however, the long-run growth in the recurrent-bubble equilibrium can be higher than the long-run growth in the fundamental equilibrium. But the growth in the recurrent-bubble equilibrium will be bumpy, disrupted by the occasional bursting of bubbles. This result is reminiscent of Ranciere, Tornell, and Westermann (2008), who document that countries that have experienced occasional financial crises have grown faster on average. Our model is consistent with their findings if we interpret the bursting of bubbles as a financial crisis as in Kindleberger (2001), at least for economies with underdeveloped financial systems. However, for economies with advanced financial systems, our model provides a different prediction; in such an economy, recurrent bubbles are harmful to economic growth in the long run.

\subsection{Welfare Analysis}

So far, we have discussed the growth impact of bubbles. But high growth in the bubbly equilibrium does not necessarily mean high welfare in the same equilibrium for at least two reasons. First, we have to consider other variables affecting utility, specifically, leisure and consumption. Second, we have to factor in volatility. Remember that not only the speed of capital accumulation but also both hours worked and consumption relative to capital stock are affected by regime switches. The welfare impact of bubbles has to be judged with all these factors taken into account.

For this purpose, we derive the welfare measure from the utility function. First, we rewrite the utility function (3) in the recursive form:

$$
V_{t}=(1-\beta)\left\{\log \left[c_{t}\right]+(1-\pi) \eta \log \left[1-l_{t}\right]\right\}+\beta E_{t}\left[V_{t+1}\right]
$$

Here, $c_{t}$ is the common consumption level across members of the household $\left(c_{t} \equiv c_{t}^{i}=c_{t}^{s}\right)$, which is an implication of the log utility. We keep assuming that $a_{t}=b_{t}=0$ for all $t$ in this section. Because both the continuation utility value $V_{t}$ and the consumption level $c_{t}$ have trends, we detrend them and rewrite the equation as follows:

$$
\hat{V}_{t}=(1-\beta)\left\{\log \left[\hat{c}_{t}\right]+(1-\pi) \eta \log \left[1-l_{t}\right]\right\}+\beta \log \left[g_{t}\right]+\beta E_{t}\left[\hat{V}_{t+1}\right]
$$

where $\hat{V}_{t}$ and $\hat{c}_{t}$ are defined as $\hat{V}_{t} \equiv V_{t}-\log K_{t}$ and $\hat{c}_{t} \equiv c_{t} / K_{t}$ respectively, and $g_{t}$ is capital growth $g_{t}=K_{t+1} / K_{t}$. $\hat{V}_{t}$ is our welfare measure. ${ }^{23}$

The solid blue line in Figure 3 plots the welfare level in the fundamental equilibrium. ${ }^{24}$ It resembles the solid blue line in Figure 1, which suggests the importance of economic growth as a determinant of welfare. We confirm this observation using a factor decomposition. Namely, we

\footnotetext{
${ }^{23}$ We borrow this welfare concept in a non-stationary setup from Schmitt-Grohe and Uribe (2005).

${ }^{24}$ Without loss of generality, we subtract the welfare level in an economy with sufficiently loose financial constraints from $\hat{V}_{t}$ before plotting it in Figure 3.
} 


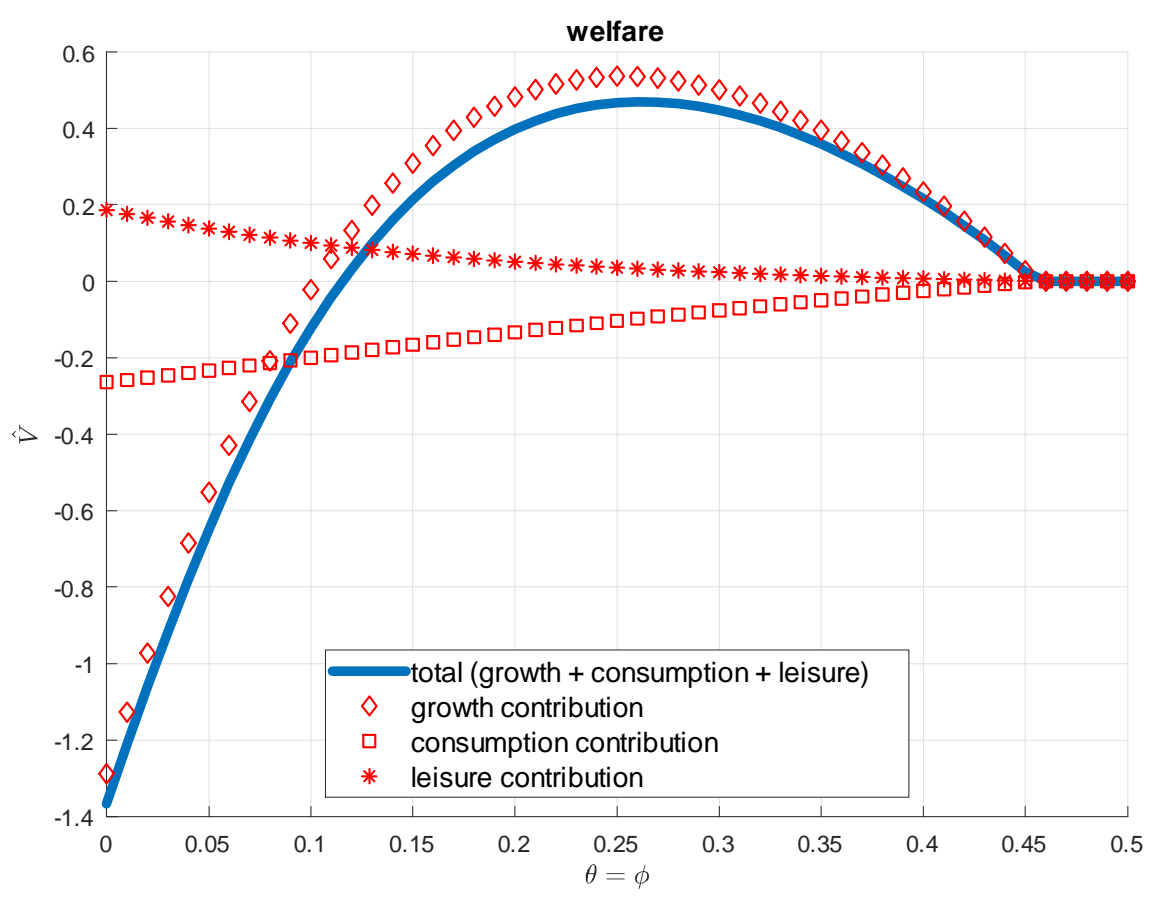

Figure 3: Financial Frictions and Welfare in Fundamental Equilibrium

vary the detrended level of consumption, hours worked, and economic growth one by one, while keeping the other two variables constant at their values observed in an economy with sufficiently loose financial constraints. We plot the welfare in each of these exercises in red squares (consumption contribution), stars (leisure contribution), and diamonds (growth contribution), respectively. If they are added up vertically, we recover total welfare. The consumption contribution monotonically increases with the level of financial development, but the leisure contribution decreases with it. This is because people not only consume more but also work longer in an economy with a developed financial system, as shown in Figure 2. With these two margins offsetting each other, economic growth emerges as the crucial factor for welfare.

Figure 4 plots the welfare levels in the recurrent-bubble equilibrium. We calculate the regimedependent welfare levels by solving the following equations:

$$
\begin{aligned}
\left(\begin{array}{c}
\hat{V}_{f r} \\
\hat{V}_{b r}
\end{array}\right)= & \left(\begin{array}{c}
(1-\beta)\left\{\log \left[\hat{c}_{f r}\right]+(1-\pi) \eta \log \left[1-l_{f r}\right]\right\}+\beta \log \left[g_{f r}\right] \\
(1-\beta)\left\{\log \left[\hat{c}_{b r}\right]+(1-\pi) \eta \log \left[1-l_{b r}\right]\right\}+\beta \log \left[g_{b r}\right]
\end{array}\right) \\
& +\left(\begin{array}{cc}
1-\sigma_{f} & \sigma_{f} \\
\sigma_{b} & 1-\sigma_{b}
\end{array}\right)\left(\begin{array}{c}
\beta \hat{V}_{f r} \\
\beta \hat{V}_{b r}
\end{array}\right)
\end{aligned}
$$

where the subscripts $f r$ and $b r$ denote the fundamental and bubbly regimes, respectively. We also 


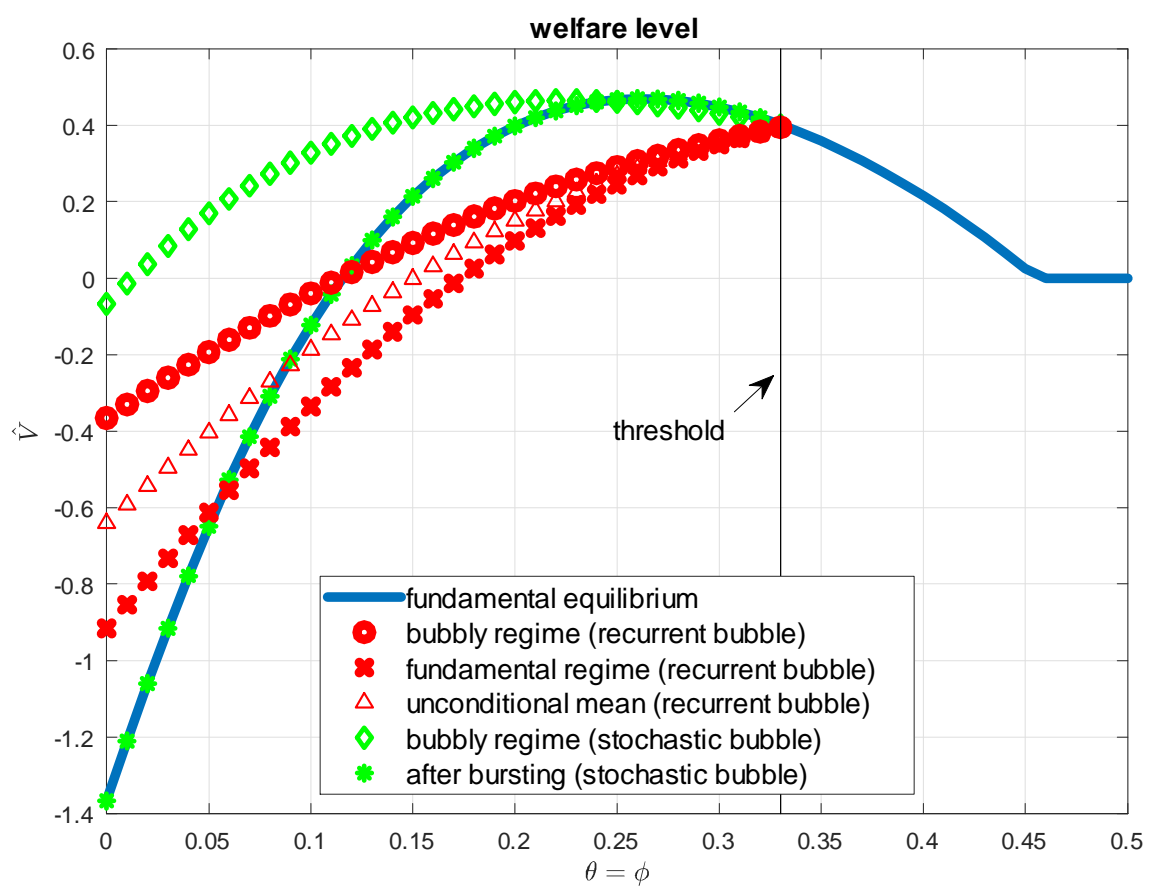

Figure 4: Financial Frictions and Welfare in Bubbly Equilibrium

calculate the unconditional welfare level in the recurrent-bubble equilibrium by

$$
\hat{V}_{b e} \equiv \frac{\sigma_{b}}{\sigma_{b}+\sigma_{f}} \hat{V}_{f r}+\frac{\sigma_{f}}{\sigma_{b}+\sigma_{f}} \hat{V}_{b r} .
$$

They are shown in red triangles $\left(\hat{V}_{b e}\right)$, crosses $\left(\hat{V}_{f r}\right)$, and circles $\left(\hat{V}_{b r}\right)$ in Figure 4 . The red triangles are above the blue line in the leftmost part of the figure. The same pattern is observed in Figure 1. Therefore, for economies with underdeveloped financial systems, recurrent bubbles are not only growth enhancing but also welfare improving in the long run. Although recurrent bubbles make the economy more volatile, the welfare loss from this channel is minor compared to the welfare gain from the boosted long-run growth. In contrast, recurrent bubbles reduce welfare in the long run if the economy has a relatively developed financial system. This is not surprising because bubbles reduce long-run growth and increase the volatility in such an economy.

Interestingly, the distance between the outcomes in the bubbly regime (red circles) and in the fundamental regime (crosses) is compressed in Figure 4 compared to Figure 1. Expectations are crucial for this result. The bubbly-regime welfare is relatively low, even though growth in the same regime is relatively high, because people anticipate that the bubble will eventually collapse. Similarly, people are not depressed in the fundamental regime despite the poor growth performance in the same regime because they expect that bubbles will emerge again in the future.

Figure 4 also shows the regime-dependent welfare levels in the stochastic-bubble equilibrium. 
The bubbly-regime welfare in this equilibrium (green diamonds) is higher than the bubbly-regime welfare in the recurrent-bubble equilibrium (red circles). This result is interesting because the stochastic-bubble equilibrium has fewer bubbly episodes (only once) than the recurrent-bubble equilibrium. But remember that although realized bubbles crowd in investment, the expectation about future bubbles crowds out investment in both the fundamental and the bubbly regimes. The bubbly-regime welfare in the stochastic-bubble equilibrium is particularly high because it is in the special situation in which the crowding-in effect of realized bubbles exists but the crowding-out effect of future bubbles does not. This is a formalization of our claim in the introduction; the analysis with the stochastic bubble emphasizes the upside of bubbles (crowding-in effect of realized bubbles) disproportionately but it abstracts from the downside (crowding-out effect) coming from future bubbles.

The tradeoff between the crowding-in effect of realized bubbles and the crowding-out effect of future bubbles becomes even more transparent by analyzing the welfare impact of high-frequency bubbles. $^{25}$ Specifically, we change $\sigma_{f}$ while keeping the other parameters, including $\sigma_{b}$, constant. Hence, bubbles emerge at different frequencies across simulations in the otherwise identical economies. Importantly, the expected duration of each bubbly episode is constant. Results are shown in Figure 5, where we plot the welfare gain of having high- or low-frequency bubbles relative to the benchmark calibration $\sigma_{f}=1.5 \%$. Namely, we plot $\hat{V}_{b e}\left(\sigma_{f}\right)-\hat{V}_{b e}(1.5 \%)$ where $\hat{V}_{b e}\left(\sigma_{f}\right)$ is the unconditional welfare level in the recurrent-bubble equilibrium defined by (24). Blue signs show the welfare gains of high-frequency bubbles $\left(\sigma_{f}>1.5 \%\right)$, and pink signs show the welfare gains of low-frequency bubbles $\left(\sigma_{f}<1.5 \%\right)$. The red line shows their counterpart of the benchmark calibration $\left(\sigma_{f}=1.5 \%\right)$, which is trivially zero.

We see a shape like a flounder. Its tail fin is almost below the red line, creating a parameter region in which both blue and pink signs are negative. For this parameter region, neither high- nor low-frequency bubbles are preferred to the benchmark calibration of $\sigma_{f}=1.5 \%$. Moreover, the fact that its belly is blue (high-frequency bubbles) and its back is pink (low-frequency bubbles) implies that the optimal (welfare-maximizing) frequency of bubbles decreases with the level of financial development. The intuition is simply put. If the economy's financial system is severely underdeveloped, high-frequency bubbles are preferred because they can mitigate the liquidity shortage, which is the major growth bottleneck in such an economy. But as the financial market gradually develops, lower-frequency bubbles start to be preferred because the liquidity shortage becomes a less urgent issue. Instead, the crowding-out effect of future bubbles emerges as a new problem. The crowding-out effect gets weaker as bubbles become less frequent because households count on bubbles less if they are unlikely to occur.

\footnotetext{
${ }^{25}$ The authors thank Jean Tirole for the discussion that led us to this exercise.
} 


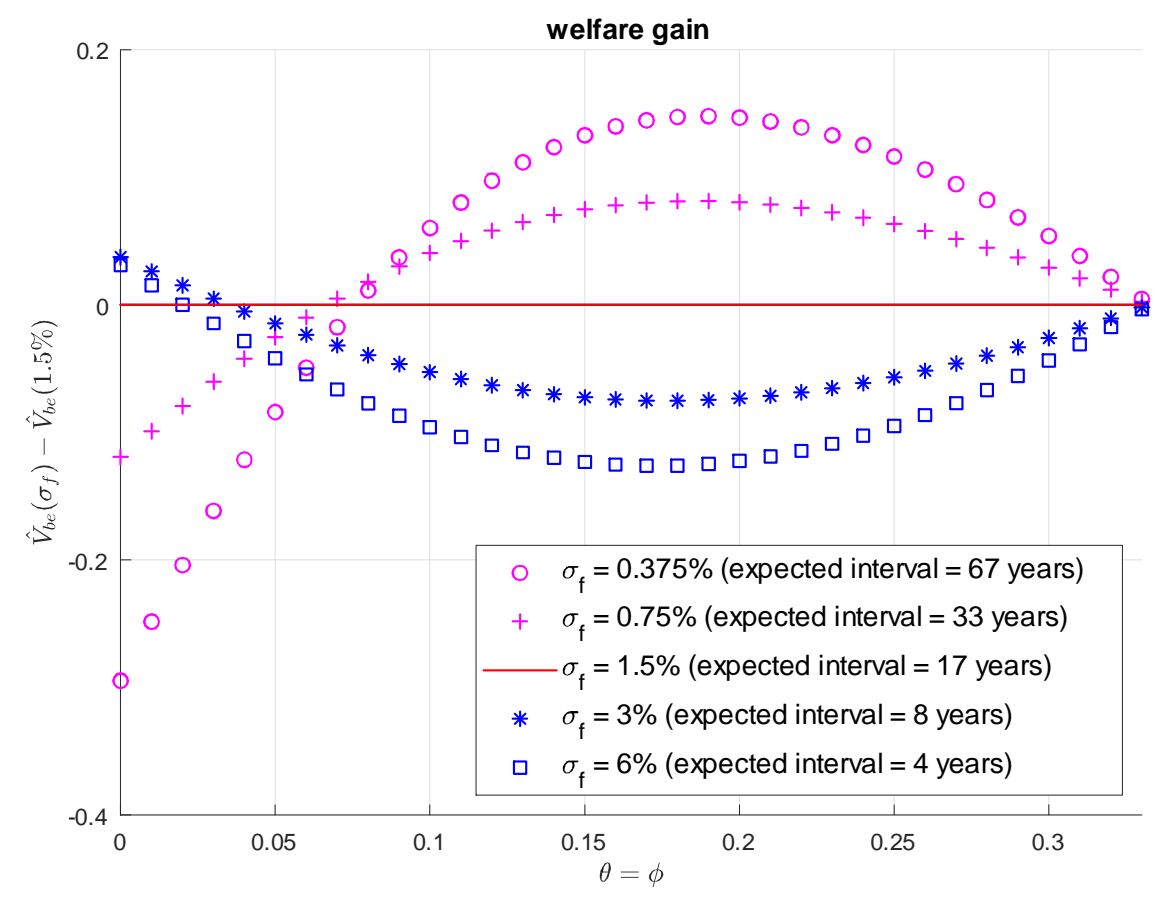

Figure 5: Frequency of Bubbles and Welfare

\section{Taking the Model to the Data}

In this section, we revisit the economic performance of the U.S. through the lens of our model. Specifically, we use quarterly U.S. data on GDP growth and the stock-market-to-GDP ratio for the period 1984.Q1-2017.Q4 to estimate the likelihood of bubbles as well as the paths of productivity and preference shocks in our model. ${ }^{26}$ We choose these observables because our model has sharp predictions about them. That is, not only is GDP growth high but also the stock market booms when bubbles exist, as we discussed in the previous section.

Figure 6 shows the observables. From the 10-year rolling-window average (red line), it is clear that GDP growth contains a slowly declining component, going from $0.7 \%$ ( $2.8 \%$ in annual terms) in the $1990 \mathrm{~s}$, to $0.87 \%(3.5 \%)$ in 2005 , to less than $0.4 \%$ (1.6\%) after the Great Recession. In contrast, the stock market-to-GDP ratio shows three boom episodes: before Black Monday in 1987, the IT bubble in the 1990s, and the late 2000s. ${ }^{27}$ Our identification strategy exploits this connection between growth and the stock market valuation to uncover the presence of bubbles in the data. For example, during the years leading up to the Great Recession, GDP growth was high, averaging $3 \%$ per year (black circles in Figure 6), and the stock-market-to-GDP ratio expanded aggressively, peaking in 2007 (about 44 percentage points higher than its value at the beginning of the 2002-2007 expansionary cycle). We observe the opposite during the post-crisis

\footnotetext{
${ }^{26}$ The detailed explanation of the data is in the appendix.

${ }^{27}$ Stock-market-to-GDP ratio is de-trended.
} 

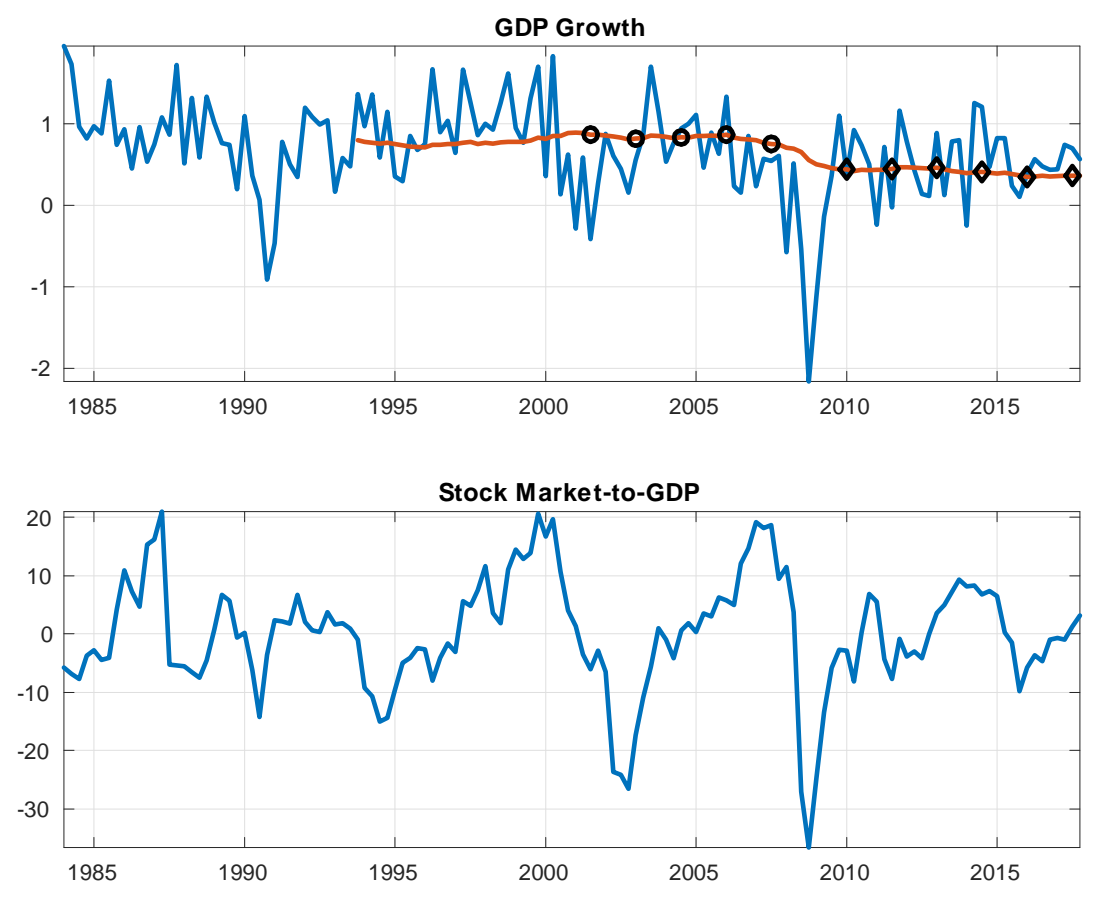

Figure 6: GDP Growth and Stock Market-GDP Ratio in Data

years: lackluster growth of $1.6 \%$ (black diamonds) and a sharp contraction in the stock market, dropping more than $55 \%$ and reaching its lowest level in the sample. These observations suggest that the economy was in the bubbly regime before 2007; the 2008 crash followed; and since then, the economy has been in the fundamental regime. But this is one potential interpretation. In an alternative interpretation of the data, the boom and bust episodes have nothing to do with bubbles but are driven by real factors, more precisely, productivity and preference shocks. Therefore, the estimation exercise is informative, because it tells us the likeliest scenario in light of the data.

We estimate the model using Bayesian methods (Fernandez-Villaverde, Rubio-Ramirez, and Schorfheide (2016)) and a non-linear filter (Kim and Nelson (1999)). We assume that the economy is in the bubbly equilibrium (see the appendix for details on the solution and estimation of the model). ${ }^{28}$ We impose the condition that the productivity and preference shocks follow an $\operatorname{AR}(1)$ process, and estimate the persistence, $\rho_{i}$, and standard deviation, $S D_{i}$, of these stochastic processes $(i=\{$ productivity $(a)$, preference $(b)\})$. We impose standard beta and inverse-gamma priors for these parameters (see Fernandez-Villaverde, Guerron-Quintana, and Rubio-Ramirez (2015) for priors on persistence parameters and Fernandez-Villaverde, Rubio-Ramirez, and Schorfheide (2016) for priors on volatility parameters). Except for $\theta$ and $\phi$, all parameter values are those

\footnotetext{
${ }^{28}$ Our model falls within the class of MS-DSGE models discussed in Farmer, Waggoner, and Zha (2009). We find a minimum-state-variable equilibrium. The absence of endogenous state variables greatly simplifies the solution method, as otherwise we would have to rely on the methods in Farmer, Waggoner, and Zha (2011).
} 

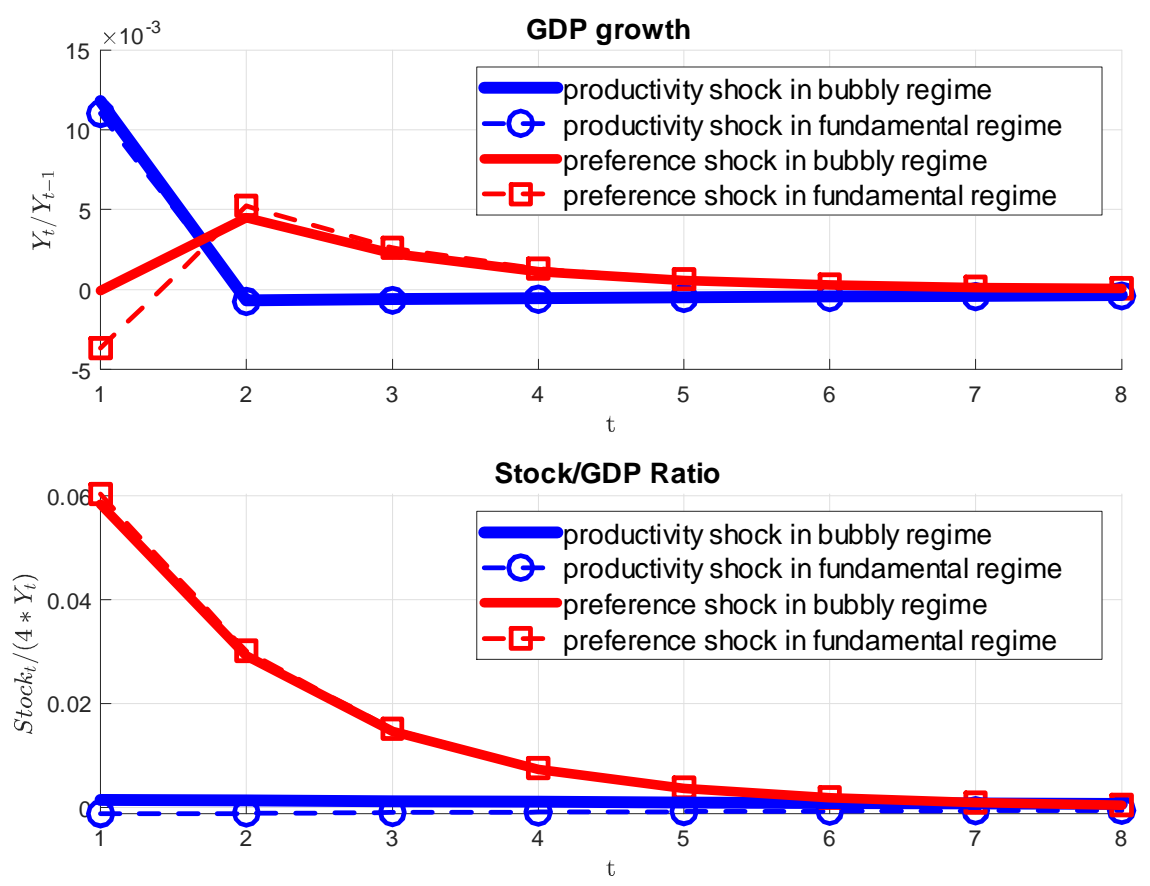

Figure 7: Impulse Response Functions

calibrated and reported in Table 1. Recall that we treated $\theta$ and $\phi$ as free parameters in the previous sections, since our objective there was to inspect the model's mechanisms. In this section, we choose $\theta=\phi=0.19$, which is in line with Kiyotaki and Moore (2019).

Figure 7 shows that the two shocks cause different dynamics on the observables. ${ }^{29}$ As shown in blue lines, a positive productivity shock (a rise in $a_{t}$ ) raises GDP growth temporarily but has a mild impact on the stock-market-to-GDP ratio because it raises both GDP and the stock market simultaneously. As shown in red lines, a positive preference shock (a rise in $b_{t}$ ) raises the stock market-to-GDP ratio by making people effectively patient. ${ }^{30}$ As a result, this shock increases investment, leading to mildly high GDP growth in subsequent periods. Impulse response functions are modestly regime-dependent. The appendix has a more detailed discussion.

As explained above, the bubbly regime in our model is characterized by both a higher stockmarket-to-GDP ratio and higher economic growth. This prediction is qualitatively robust. Once calibrated, the model has quantitative predictions for the means of those variables in each regime too. However, these predictions may not match their "data counterparts," by which we mean the true regime-dependent means of GDP growth and the stock-market-to-GDP ratio that would be

\footnotetext{
${ }^{29}$ We set $\left(\rho_{a}, \rho_{b}\right)=(0.9,0.5)$ and $\left(S D_{a}, S D_{b}\right)=(0.01,0.08)$, which are roughly our estimated values. Responses to one-standard-deviation innovations to structural shocks are plotted. Results are qualitatively robust to other parameter values.

${ }^{30}$ After the shock, households end up putting large weights to the utility flows in the distant future relative to those in the near future because the preference shock is mean reverting.
} 
calculated from the data if we perfectly knew when bubbles existed in the U.S. economy. Moreover, we do not want to use them as calibration targets, because that exercise needs to take an a priori stance on the timing of the regime switch before estimating it. To work around this issue, we propose the following procedure. When we estimate the regimes, we also estimate the average capital growth (a key determinant of economic growth) in the data, if in the fundamental regime, $\mu_{g, f}$, as the sum of the model's implied capital growth in the fundamental regime, $\mu_{g, f}^{m}$, and an offsetting constant, $\bar{\mu}_{g, f}\left(\mu_{g, f}=\mu_{g, f}^{m}+\bar{\mu}_{g, f}\right)$. Here, the constant makes up for the difference between the model and the data. A similar strategy is imposed on capital growth in the bubbly regime and the stock-market-to-GDP ratio in the two regimes. It is worth stressing that our findings are robust to alternative calibration and identification strategies such as 1) using $\theta$ and $\phi$ to match the means of GDP growth and the credit-to-GDP ratio in and out of the Great Recession, with the caveat that we impose the dates when bubbles exist a priori; 2) a longer sample; 3) using GDP growth and credit market data as observables; 4) a third regime featuring high growth and a high credit-to-GDP ratio driven by non-bubble forces; and 5) GDP growth and the consumptionto-investment ratio as observables (for details, see the appendix and a previous working paper version).

We use normal priors for the means of capital growth and the stock-market-to-GDP ratio in the fundamental and bubbly regimes, $\left\{\mu_{g, f}, \mu_{\text {stock } / G D P, f}, \mu_{g, b}, \mu_{\text {stock } / G D P, b}\right\}$, respectively. Table 2 presents both the priors and posteriors (mode and $90 \%$ credible bands) from the estimation. The priors and posteriors are different, which points to the informativeness of the data. Importantly, the posterior modes indicate that both capital growth and the stock-market-to-GDP ratio are higher during the bubbly regime than during the fundamental regime. For example, the average capital growth is estimated to be about 52 basis points higher in annual terms in the presence of bubbles than in periods without them. In terms of the structural shocks, the preference disturbance is volatile but lacks persistence, while the productivity shock is relatively persistent and stable. ${ }^{31}$ Interestingly, the estimated persistence of productivity is lower than the typical number in the literature $(\approx 0.95)$, which is a consequence of the persistence introduced by the endogenous productivity and the regime switching.

\subsection{Results}

Figure 8 presents the estimated probability of the bubbly regime. The economy spent most of the time in the fundamental regime before 1997, with a brief exception prior to 1987, which was abruptly terminated by Black Monday. Therefore, relatively strong economic growth during the first 10 years or so of the sample was mainly driven by real shocks plotted in Figure 9. This result is not surprising given the moderate stock-market-to-GDP ratio observed in the data in

\footnotetext{
${ }^{31}$ We tried alternative means and standard deviations for the priors. Our results are robust to these variations. This should not be surprising given how tightly estimated the parameters are.
} 


\begin{tabular}{ccc}
\hline Parameter & Prior & Posterior \\
\hline$\mu_{g, f}$ & $N(0.5,0.1)$ & 0.65 \\
$\mu_{\text {stock } / G D P, f}$ & $N(0.56,0.75]$ \\
$\mu_{g, b}$ & $N(0.75,0.1)$ & -1.67 \\
& {$[-2.95,-0.45]$} \\
& 0.78 \\
$\mu_{\text {stock } / G D P, b}$ & $N(10,1)$ & {$[0.63,0.93]$} \\
$\rho_{b}$ & $B(0.15,0.05)$ & {$[8.81,11.87]$} \\
$S D_{b}$ & $I G(6,1)$ & 0.50 \\
& $B(0.40,0.58]$ \\
$\rho_{a}$ & $B(0.75,0.05)$ & {$[0.07,0.09]$} \\
$S D_{a}$ & $I G(6,1)$ & $0.85,0.92]$ \\
& & 0.01 \\
\end{tabular}

Table 2: Estimated Parameters

this period. During the second half of the 1990s, a combination of positive productivity shocks and the emergence of the bubble raises both GDP growth and stock market value. This bubble, according to our model, started around 1997 and ended in the second quarter of 2001. Because of this timing, we call it the "IT bubble." 32

After the IT bubble crash, the probability of the bubbly regime rose up again in 2006, raising both GDP growth and the stock market. By mid 2006, the probability exceeded 50\%, and between 2007 and mid 2008, it came close to 100\%. We call it the "housing bubble" because of its timing. Importantly, high growth in this period is mainly driven by the bubble; notice that productivity shocks are unfavorable in this period. This is different from the economic boom in the mid 1990s, which was driven by favorable real shocks. The Great Recession was caused by the collapse of the housing bubble and highly unfavorable real shocks. We suspect that the particularly adverse preference innovation in this period reflects adverse financial shocks that we do not model explicitly in this paper. ${ }^{33}$

The return to the fundamental regime mixed with adverse productivity shocks explains the lackluster performance of the U.S. economy during the last decade. In the final part of the sample, our approach assigns some probability that the economy experienced a new and short-lived bubble. In the data, growth was relatively strong in 2014, and so was the stock market in the midst of ultraloose monetary policies around the world. But the evidence is not strong enough to determine with certainty that a bubble was present. According to our model, the chance was less than $50 \%$.

Interestingly, the timing of the regime switches in our model does not resemble estimates in other regime-switching models advanced in the literature. For example, Sims and Zha (2006) fit U.S. data to a regime-switching VAR with drifting coefficients and variances. They report

\footnotetext{
${ }^{32}$ Strictly speaking, our one-sector model has no reason to connect this bubble to the information technology sector. We nonetheless use this term for convenience. The same applies to the "housing bubble."

${ }^{33}$ See Guerron-Quintana and Jinnai (2019) for more discussion on the financial market and the Great Recession.
} 


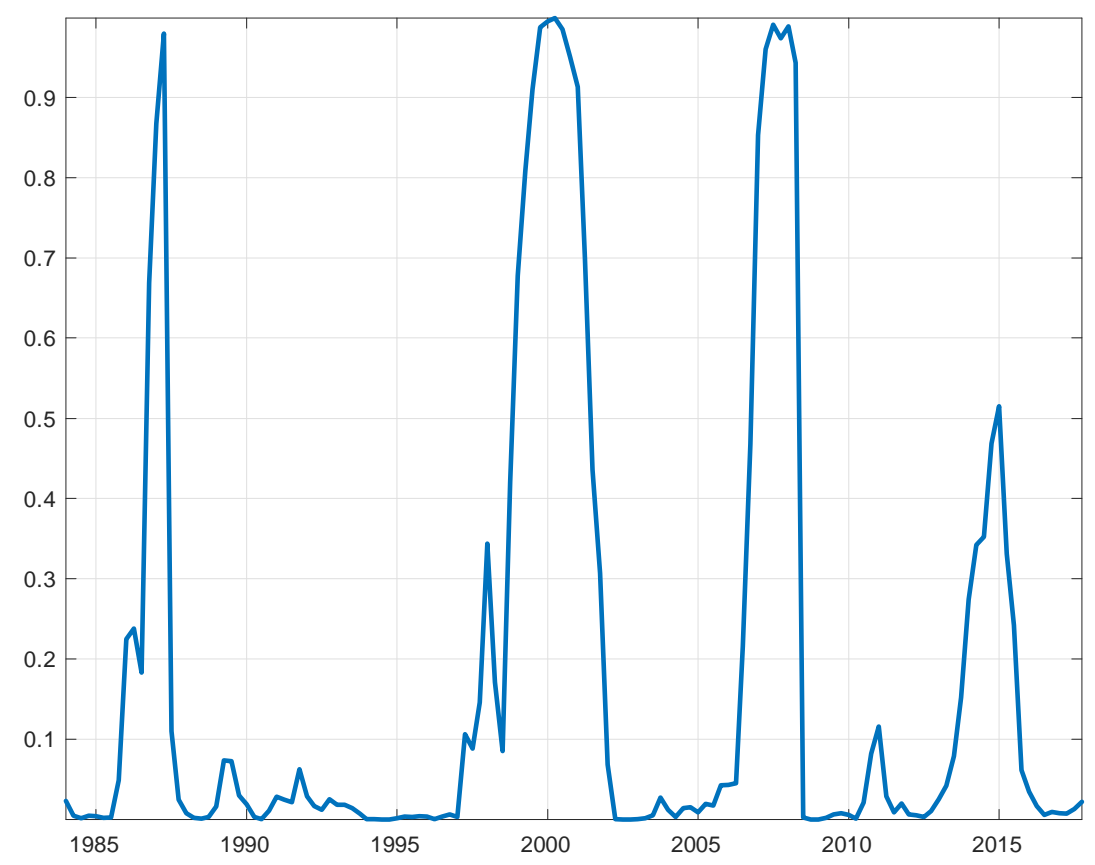

Figure 8: Probability of Bubbly Regime

the existence of four distinct regimes: the Greenspan state prevailing during the 1990s and early 2000s; the second most common regime emerges in the early 1960s and parts of the 1970s; the last two regimes correspond to sporadic events such as 9/11. Our estimates are not similar to those estimated to account for the Great Moderation, with a high volatility regime prior to 1984 and a calmer one post-1984 (Stock and Watson (2002)). Finally, our estimates bear little resemblance to recession regimes (Chauvet and Piger (2008)). See Hamilton (2016) for an extensive review of regime switching in macroeconomics.

How important were these bubbles? We answer this question by two counterfactual simulations. The first one is the "no-bubble-by-chance" simulation, in which the probability of the economy being in the bubbly regime was artificially set at zero. In this scenario, the economy is still in the recurrent-bubble equilibrium; it is only the realization of the regime that we change. The dashed red line in Figure 10 shows the trend of log GDP under this counterfactual scenario. ${ }^{34}$ The solid blue line shows the GDP trend in the benchmark scenario. It is clear from this exercise that the bubble has both short-run and middle-run impacts on the economy. The short-run impact is the economic boom directly caused by the realized bubble, i.e., a "plateau" made by the solid blue line and the dashed red line in the middle of each panel. This economic boom is the result of

\footnotetext{
${ }^{34}$ It is normalized to 0 in 1997 in the upper panel and in 2005 in the lower panel. To facilitate the comparison across simulations, we shut down the structural shocks. Its impact on the result is minor because responses to structural shocks are only mildly regime-dependent (see Figure 7).
} 

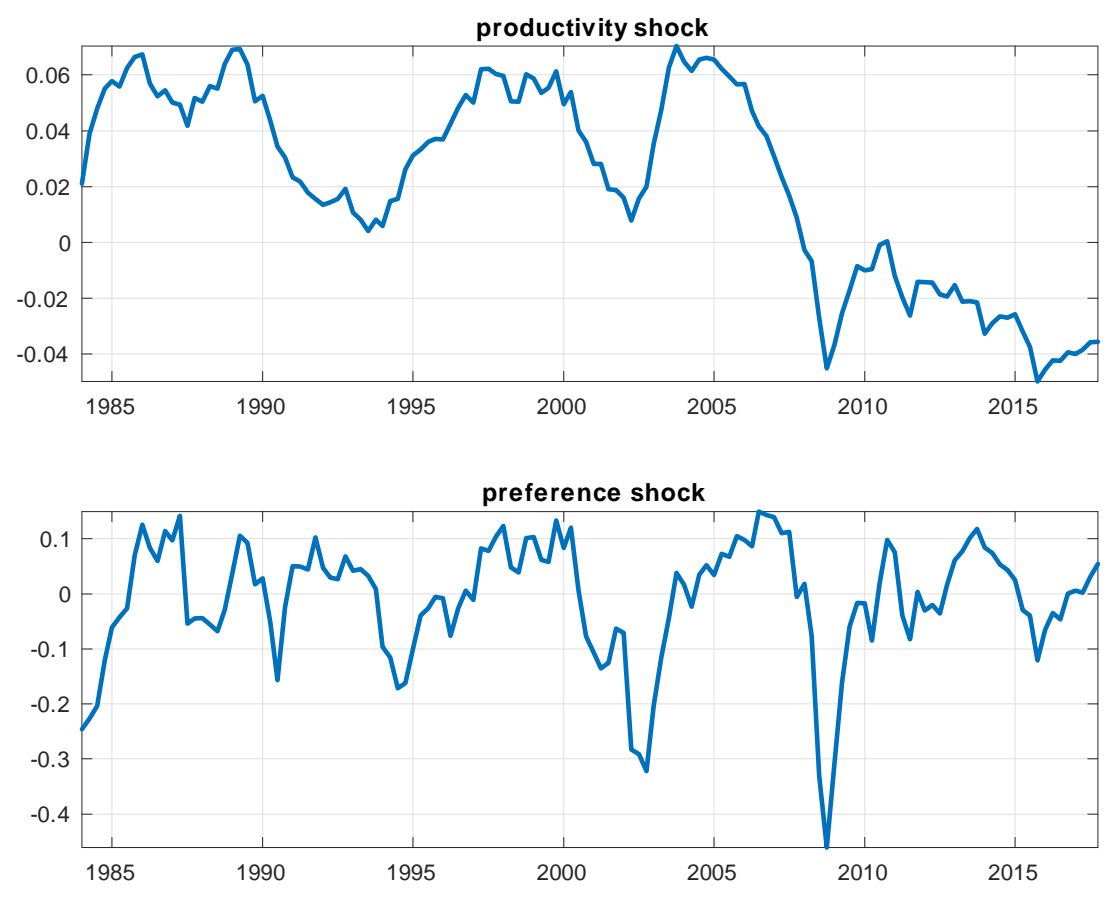

Figure 9: Estimated Preference and Productivity Shocks

the inter-regime substitution discussed in the previous section. According to our estimate, the short-run impact is already sizable; by about 6 to 7 percentage points more goods and services were produced during the economic booms.

The medium-run impact is subtle but important too. Notice that the solid blue line is higher than the dashed red line even after the bubble is gone. This is because the solid blue line and the dashed red line are not exactly parallel when bubbles exist, but the solid blue line has a steeper slope when they do. This is a graphical confirmation that capital growth is higher in the bubbly regime than in the fundamental regime as shown in Figure 1. As for the IT bubble, the GDP trend is about 1.2 percentage point higher in the baseline scenario in the years after the bubble burst. As for the housing bubble, it is about 60 basis points. Combined, the two bubbles permanently raised the level of U.S. GDP by about 2 percentage points than in the scenario in which bubbles did not materialize by chance.

Our second exercise is the "no-chance-of-bubble" simulation, by which we mean that the economy is in the fundamental equilibrium. Hence, bubbles were neither realized nor expected to do so. The trend line under this scenario corresponds to the dotted black line in Figure 10. Clearly, the economy would have grown at the fastest pace in this scenario. This is because of the absence of the crowding-out effect of future bubbles; had people not expected bubbles to emerge, they would have consumed less, worked more, and invested more, all of which would have contributed 

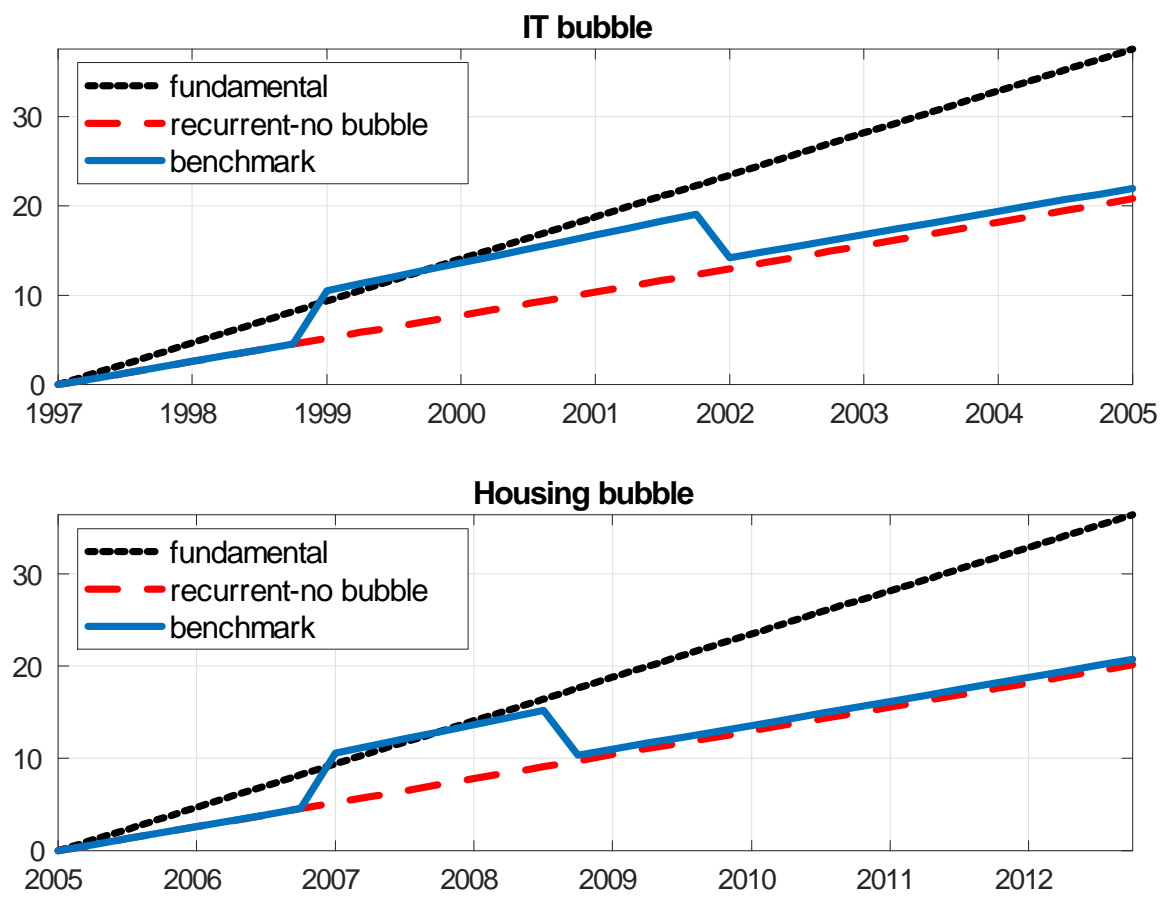

Figure 10: Counterfactual Scenarios

to higher growth. So our model suggests that realized bubbles are better than no realization, but if we could move to a different equilibrium in which bubbles are not expected by economic agents, that would be better.

\section{Conclusions}

We examine implications of a regime-switching recurrent bubble model with endogenous growth. Unlike the previous work in the literature (Kocherlakota (2009), Farhi and Tirole (2012), Martin and Ventura (2012), and Hirano and Yanagawa (2017)), our model has infinitely lived households that experience not only the complete crash of existing bubbles but also the emergence of asset bubbles attached to a new vintage of bubbly assets. We find a novel crowding-out effect of asset bubbles; that is, expectations about the emergence of future bubbles increase both consumption and leisure, decrease both investment and labor supply, and hence slow down economic growth. This type of crowding-out effect is not emphasized in the literature. We find that both the welfare and growth implications of asset bubbles depend on a balance between the crowding-in effect of realized bubbles and the crowding-out effect of future bubbles, which in turn depends on the level of financial development and the frequency of recurrent bubbles.

Regarding policy implications, our analysis suggests that leaning against the bubble policy 
may be recommended to economies whose financial markets are developed. ${ }^{35}$ This is because such economies will not benefit from the crowding-in effect of realized bubbles much, but should worry more about the crowding-out effect of future bubbles. Complete elimination of bubbles might not be easy in practice, but if the frequency of bubbles can be reduced, that would already be a step in the right direction, our model suggests. On the other hand, if the financial market is underdeveloped, leaning with the bubble policy might promote growth and welfare. Increasing the frequency of bubbles might not be a bad idea either. But it needs to be done with caution because the welfare-maximizing frequency of bubbles is country specific.

We examine U.S. economic growth performance through the lens of our recurrent-bubble model. We find that booms in the mid-1990s and the mid-2000s were driven by distinct forces; the former was driven by improvement in exogenous productivity, while the latter was driven by the emergence of an asset price bubble. The lackluster recovery from the Great Recession was due to a combination of the bursting of the asset price bubble and unlucky draws of exogenous shocks. A counterfactual simulation reveals that both the IT and housing bubbles lifted GDP significantly. But another counterfactual simulation reveals that U.S. economic growth performance would be better in the hypothetical, but theoretically possible, equilibrium in which bubbles never arise nor are expected. So actual realization of a bubble is better than no realization by chance. But an even better scenario is that the U.S. economy moves to another equilibrium in which bubbles never arise in the future and people recognize this.

\section{References}

Allen, F., G. Barlevy, And D. Gale (2017): "On Interest Rate Policy and Asset Bubbles," Unpublished Manuscript.

Arrow, K. J. (1962): "The Economic Implications of Learning by Doing," The Review of Economic Studies, 29(3), pp. 155-173.

Barlevy, G. (2018): "Bridging Between Policymakers' and Economists' Views on Bubbles," Economic Perspectives, 42(4), 1-21.

Bassett, W., A. Daigle, R. Edge, and G. Kara (2015): "Credit-to-GDP Trends and Gaps by Lender- and Credit-Type," FEDS Notes. December 3, 2015, Washington: Board of Governors of the Federal Reserve System.

Bewley, T. (1980): "The optimum quantity of money," in Models of Monetary Economies, ed. by J. Kareken, and N. Wallace, pp. 169-210. Federal Reserve Bank of Minneapolis.

\footnotetext{
${ }^{35}$ See Gali (2014), Hirano, Inaba, and Yanagawa (2015), and Allen, Barlevy, and Gale (2017) for a discussion of asset price bubbles and government policy.
} 
Biswas, S., A. Hanson, and T. Phan (2018): "Bubbly Recessions," Working Paper No. 18-05, Federal Reserve Bank of Richmond.

Blanchard, O., E. Cerutti, and L. Summers (2014): "Inflation and Activity - Two Explorations, and Their Monetary Policy Implications," Discussion paper, ECB Forum on Central Banking.

Brunnermeier, M. K., and M. Oehmke (2013): "Bubbles, Financial Crises, and Systemic Risk," in Handbook of the Economics of Finance, ed. by G. M. Constantinides, M. Harris, and R. M. Stulz, vol. 2, chap. 18, pp. 1221 - 1288. Elsevier.

Brunnermeier, M. K., and Y. Sannikov (2014): "A Macroeconomic Model with a Financial Sector," American Economic Review, 104(2), 379-421.

Cerra, V., and S. C. Saxena (2008): "Growth Dynamics: The Myth of Economic Recovery," American Economic Review, 98(1), 439-57.

Chauvet, M., and J. Piger (2008): "A Comparison of the Real-Time Performance of Business Cycle Dating Methods," Journal of Business \& Economic Statistics, 26(1), 42-49.

Comin, D., And M. Gertler (2006): "Medium-Term Business Cycles," American Economic Review, 96, 523-551.

Del Negro, M., G. Eggertsson, A. Ferrero, and N. Kiyotaki (2017): "The Great Escape? A Quantitative Evaluation of the Fed's Liquidity Facilities," American Economic Review, $107(3), 824-57$.

Diba, B. T., and H. I. Grossman (1988): "The Theory of Rational Bubbles in Stock Prices," The Economic Journal, 98(392), 746-754.

Farhi, E., and J. Tirole (2012): "Bubbly Liquidity," The Review of Economic Studies, 79(2), 678.

Farmer, R. E., D. F. Waggoner, and T. Zha (2009): "Understanding Markov-switching rational expectations models," Journal of Economic Theory, 144(5), 1849 - 1867.

(2011): "Minimal state variable solutions to Markov-switching rational expectations models," Journal of Economic Dynamics and Control, 35(12), 2150 - 2166, Frontiers in Structural Macroeconomic Modeling.

Fernandez-Villaverde, J., P. Guerron-Quintana, and J. F. Rubio-Ramirez (2015): "Estimating dynamic equilibrium models with stochastic volatility," Journal of Econometrics, 185(1), 216 - 229 . 
Fernandez-Villaverde, J., J. Rubio-Ramirez, and F. Schorfheide (2016): "Solution and Estimation Methods for DSGE Models," in Handbook of Macroeconomics, ed. by J. B. Taylor, and H. Uhlig, vol. 2, chap. 9, pp. 527 - 724. Elsevier.

Gali, J. (2014): "Monetary Policy and Rational Asset Price Bubbles," American Economic Review, 104(3), 721-52.

(2016): "Insider-outsider labor markets, hysteresis and monetary policy," Economics Working Papers 1506, Department of Economics and Business, Universitat Pompeu Fabra.

Gertler, M., and N. Kiyotaki (2015): "Banking, Liquidity, and Bank Runs in an Infinite Horizon Economy," American Economic Review, 105(7), 2011-43.

Gertler, M., N. Kiyotaki, and A. Prestipino (2020): "A Macroeconomic Model with Financial Panics," The Review of Economic Studies, 87(1), 240-288.

Guerrieri, V., and H. Uhlig (2016): "Chapter 17 - Housing and Credit Markets: Booms and Busts," in Handbook of Macroeconomics, ed. by J. B. Taylor, and H. Uhlig, vol. 2, pp. 1427 1496. Elsevier.

Guerron-Quintana, P. A., and R. Jinnai (2019): "Financial frictions, trends, and the great recession," Quantitative Economics, 10(2), 735-773.

Hamilton, J. D. (2016): "Macroeconomic Regimes and Regime Shifts," in Handbook of Macroeconomics, ed. by J. B. Taylor, and H. Uhlig, vol. 2 of Handbook of Macroeconomics, chap. 3, pp. 163 - 201. Elsevier.

He, Z., and A. Krishnamurthy (2013): "Intermediary Asset Pricing," American Economic Review, 103(2), 732-70.

Hirano, T., M. Inaba, and N. Yanagawa (2015): "Asset bubbles and bailouts," Journal of Monetary Economics, 76, S71 - S89, Supplement Issue: November 7-8, 2014 Research Conference on Asset Price Fluctuations and Economic Policy.

Hirano, T., and N. Yanagawa (2017): "Asset Bubbles, Endogenous Growth, and Financial Frictions," The Review of Economic Studies, 84(1), 406-443.

Ivashina, V., and D. Scharfstein (2010): "Bank lending during the financial crisis of 2008," Journal of Financial Economics, 97(3), 319 - 338.

Jorda, O., M. Schularick, and A. M. Taylor (2015): "Leveraged bubbles," Journal of Monetary Economics, 76, S1 - S20, Supplement Issue: November 7-8, 2014 Research Conference on Asset Price Fluctuations and Economic Policy. 
Kaminigashi, T. (2011): "Recurrent bubbles," The Japanese Economic Review, 62(1), 27-62.

Kim, C.-J., And C. R. Nelson (1999): State-Space Models with Regime Switching. The MIT Press.

Kindleberger, C. P. (2001): Manias, Panics and Crashes. Wiley, 4th edn.

Kiyotaki, N., and J. Moore (2019): "Liquidity, Business Cycles, and Monetary Policy," Journal of Political Economy, 127(6), 2926-2966.

Kocherlakota, N. (2009): "Bursting Bubbles: Consequences and Cures," Unpublished Manuscript, University of Minnesota.

Kocherlakota, N. R. (1992): "Bubbles and constraints on debt accumulation," Journal of Economic Theory, 57(1), $245-256$.

Martin, A., and J. Ventura (2012): "Economic Growth with Bubbles," American Economic Review, 102(6), 3033-58.

Matsuyama, K. (2013): "The Good, the Bad, and the Ugly: An inquiry into the causes and nature of credit cycles," Theoretical Economics, 8(3), 623-651.

Matsuyama, K., I. Sushko, and L. Gardini (2016): "Revisiting the model of credit cycles with Good and Bad projects," Journal of Economic Theory, 163, 525 - 556.

Mendoza, E. G. (2010): "Sudden Stops, Financial Crises, and Leverage," American Economic Review, 100(5), 1941-66.

Miao, J., P. WAng, and Z. Xu (2015): "A Bayesian dynamic stochastic general equilibrium model of stock market bubbles and business cycles," Quantitative Economics, 6(3), 599-635.

Pham, N.-S., C. Le Van, and S. Bosi (2019): "Real indeterminacy and dynamics of asset price bubbles in general equilibrium," MPRA Paper No. 96834, Munich Personal RePEc Archive.

Ranciere, R., A. Tornell, and F. Westermann (2008): "Systemic Crises and Growth," The Quarterly Journal of Economics, 123(1), 359-406.

Romer, P. M. (1986): "Increasing Returns and Long-Run Growth," Journal of Political Economy, 94(5), 1002-1037.

Samuelson, P. A. (1958): "An Exact Consumption-Loan Model of Interest with or without the Social Contrivance of Money," Journal of Political Economy, 66(6), 467-482.

Santos, M. S., and M. Woodford (1997): "Rational Asset Pricing Bubbles," Econometrica, $65(1), 19-57$. 
Scheinkman, J. A., And L. Weiss (1986): "Borrowing Constraints and Aggregate Economic Activity," Econometrica, 54(1), 23-45.

Schmitt-Grohe, S., And M. Uribe (2004): "Solving dynamic general equilibrium models using a second-order approximation to the policy function," Journal of Economic Dynamics and Control, 28(4), $755-775$.

(2005): "Optimal Inflation Stabilization in a Medium-Scale Macroeconomic Model," Working Paper 11854, National Bureau of Economic Research.

Shell, K., M. Sidrauski, and J. E. Stiglitz (1969): "Capital Gains, Income, and Saving," The Review of Economic Studies, 36(1), 15-26.

Sheshinski, E. (1967): "Optimal accumulation with learning by doing," in Essays on the Theory of Optimal Economic Growth, ed. by K. Shell, pp. 31-52. MIT Press, Cambridge, MA.

SHI, S. (2015): "Liquidity, assets and business cycles," Journal of Monetary Economics, 70, 116 -132 .

Sims, C. A., And T. Zha (2006): "Were There Regime Switches in U.S. Monetary Policy?," American Economic Review, 96(1), 54-81.

Stock, J., And M. Watson (2002): "Has the Business Cycle Changed and Why?," NBER Macroeconomics Annual, pp. 159-230.

Tirole, J. (1982): "On the Possibility of Speculation under Rational Expectations," Econometrica, 50(5), 1163-1181.

(1985): “Asset Bubbles and Overlapping Generations," Econometrica, 53(6), 1499-1528.

Townsend, R. M. (1980): "Models of Money with Spatially Separated Agents," in Models of Monetary Economies, ed. by J. Kareken, and N. Wallace, pp. 265-303. Federal Reserve Bank of Minneapolis.

WeIL, P. (1987): "Confidence and the Real Value of Money in an Overlapping Generations Economy," The Quarterly Journal of Economics, 102(1), 1.

Woodford, M. (1990): "Public Debt as Private Liquidity," The American Economic Review, $80(2), 382-388$. 


\section{Appendix}

NOT FOR PUBLICATION

\subsection{Model Summary}

\subsubsection{Fundamental Equilibrium With Loose Financial Constraints}

When financial constraints are sufficiently loose, the equilibrium conditions are summarized as follows:

$$
\begin{gathered}
Y_{t}=\bar{A} e^{a_{t}} u_{t}^{\alpha} K_{t}\left((1-\pi) l_{t}\right)^{1-\alpha}, \\
\left(c_{t}^{i}\right)^{-\rho}=\left(c_{t}^{s}\right)^{-\rho}\left(1-l_{t}\right)^{\eta(1-\rho)}, \\
\eta \frac{c_{t}^{s}}{1-l_{t}}=w_{t}, \\
\delta^{\prime}\left(u_{t}\right)=r_{t}, \\
E_{t}\left[\frac{\beta}{e^{b_{t+1}-b_{t}}}\left(\frac{c_{t}^{i}}{c_{t+1}^{i}}\right)^{\rho}\left(u_{t+1} r_{t+1}+1-\delta\left(u_{t+1}\right)\right)\right], \\
r_{t}=\alpha \frac{Y_{t}}{u_{t} K_{t}}, \\
w_{t}=(1-\alpha) \frac{Y_{t}}{(1-\pi) l_{t}},
\end{gathered}
$$

and

$$
\pi c_{t}^{i}+(1-\pi) c_{t}^{s}+K_{t+1}-\left(1-\delta\left(u_{t}\right)\right) K_{t}=Y_{t}
$$

Detrending variables by $K_{t}$, we obtain

$$
\begin{gathered}
\hat{Y}_{t}=\bar{A} e^{a_{t}} u_{t}^{\alpha}\left((1-\pi) l_{t}\right)^{1-\alpha}, \\
\left(\hat{c}_{t}^{i}\right)^{-\rho}=\left(\hat{c}_{t}^{s}\right)^{-\rho}\left(1-l_{t}\right)^{\eta(1-\rho)}, \\
\eta \frac{\hat{c}_{t}^{s}}{1-l_{t}}=\hat{w}_{t}, \\
\delta^{\prime}\left(u_{t}\right)=r_{t}, \\
E_{t}\left[\frac{\beta}{e^{b_{t+1}-b_{t}}}\left(\frac{\hat{c}_{t}^{i}}{\hat{c}_{t+1}^{i}} \frac{1}{g_{t}}\right)^{\rho}\left(u_{t+1} r_{t+1}+1-\delta\left(u_{t+1}\right)\right)\right], \\
\hat{w}_{t}=(1-\alpha) \frac{\hat{Y}_{t}}{u_{t}} \\
(1-\pi) l_{t}
\end{gathered}
$$


and

$$
\pi \hat{c}_{t}^{i}+(1-\pi) \hat{c}_{t}^{s}+g_{t}-\left(1-\delta\left(u_{t}\right)\right)=\hat{Y}_{t}
$$

where variables with a hat denote the original variables divided by $K_{t}$, for example, $\hat{Y}_{t} \equiv Y_{t} / K_{t}$, and $g_{t}$ is capital growth defined as $g_{t} \equiv K_{t+1} / K_{t}$.

\subsubsection{Fundamental Equilibrium With Tight Financial Constraints}

Suppose that the financial constraints are sufficiently tight that they are always binding. In addition, suppose that the economy is in the fundamental equilibrium. The equilibrium conditions are summarized as follows:

$$
\begin{gathered}
Y_{t}=\bar{A} e^{a t} u_{t}^{\alpha} K_{t}\left((1-\pi) l_{t}\right)^{1-\alpha}, \\
\left(c_{t}^{i}\right)^{-\rho}=\left(c_{t}^{s}\right)^{-\rho}\left(1-l_{t}\right)^{\eta(1-\rho)}, \\
\eta \frac{c_{t}^{s}}{1-l_{t}}=w_{t}, \\
q_{t}=E_{t}\left[\frac{\beta}{e^{b_{t+1}-b_{t}}}\left(\frac{c_{t}^{i}}{c_{t+1}^{i}}\right)^{\rho}\left(u_{t+1} r_{t+1}+\left(1-\delta\left(u_{t+1}\right)\right) q_{t+1}+\pi \lambda_{t+1}\left(u_{t+1} r_{t+1}+\phi q_{t+1}\left(1-\delta\left(u_{t+1}\right)\right)\right)\right)\right], \\
r_{t}=\alpha \frac{Y_{t}}{u_{t} K_{t}}, \\
w_{t}=(1-\alpha) \frac{Y_{t}}{(1-\pi) l_{t}}, \\
Y_{t}=\pi c_{t}^{i}+(1-\pi) c_{t}^{s}+\pi \frac{\left[u_{t} r_{t}+\phi q_{t}\left(1-\delta\left(u_{t}\right)\right)\right] K_{t}}{1-\theta q_{t}},
\end{gathered}
$$

and

$$
K_{t+1}=\left(1-\delta\left(u_{t}\right)\right) K_{t}+\pi \frac{\left[u_{t} r_{t}+\phi q_{t}\left(1-\delta\left(u_{t}\right)\right)\right] K_{t}}{1-\theta q_{t}} .
$$

Detrending variables by $K_{t}$, we obtain

$$
\begin{gathered}
\hat{Y}_{t}=\bar{A} e^{a_{t}} u_{t}^{\alpha}\left((1-\pi) l_{t}\right)^{1-\alpha}, \\
\left(\hat{c}_{t}^{i}\right)^{-\rho}=\left(\hat{c}_{t}^{s}\right)^{-\rho}\left(1-l_{t}\right)^{\eta(1-\rho)}, \\
\eta \frac{\hat{c}_{t}^{s}}{1-l_{t}}=\hat{w}_{t}, \\
q_{t}=E_{t}\left[\frac{\beta}{e^{b_{t+1}-b_{t}}}\left(\frac{\hat{c}_{t}^{i}}{\hat{c}_{t+1}^{i}} \frac{1}{g_{t}}\right)^{\rho}\left(u_{t+1} r_{t+1}+\left(1-\delta\left(u_{t+1}\right)\right) q_{t+1}+\pi \lambda_{t+1}\left(u_{t+1} r_{t+1}+\phi q_{t+1}\left(1-\delta\left(u_{t+1}\right)\right)\right)\right)\right],
\end{gathered}
$$




$$
\begin{gathered}
r_{t}=\alpha \frac{\hat{Y}_{t}}{u_{t}}, \\
\hat{w}_{t}=(1-\alpha) \frac{\hat{Y}_{t}}{(1-\pi) l_{t}}, \\
\hat{Y}_{t}=\pi \hat{c}_{t}^{i}+(1-\pi) \hat{c}_{t}^{s}+\pi \frac{u_{t} r_{t}+\phi q_{t}\left(1-\delta\left(u_{t}\right)\right)}{1-\theta q_{t}},
\end{gathered}
$$

and

$$
g_{t}=1-\delta\left(u_{t}\right)+\pi \frac{u_{t} r_{t}+\phi q_{t}\left(1-\delta\left(u_{t}\right)\right)}{1-\theta q_{t}} .
$$

\subsubsection{Recurrent-Bubble Equilibrium}

Suppose that the economy is in the recurrent-bubble equilibrium. The equilibrium conditions are summarized as follows:

$$
\begin{aligned}
& Y_{t}=\bar{A} e^{a_{t}} u_{t}^{\alpha} K_{t}\left((1-\pi) l_{t}\right)^{1-\alpha}, \\
& \left(c_{t}^{i}\right)^{-\rho}=\left(c_{t}^{s}\right)^{-\rho}\left(1-l_{t}\right)^{\eta(1-\rho)}, \\
& \eta \frac{c_{t}^{s}}{1-l_{t}}=w_{t} \\
& r_{t}-\delta^{\prime}\left(u_{t}\right) q_{t}+\pi \lambda_{t}\left(r_{t}-\phi q_{t} \delta^{\prime}\left(u_{t}\right)\right)=0, \\
& q_{t}=E_{t}\left[\frac{\beta}{e^{b_{t+1}-b_{t}}}\left(\frac{c_{t}^{i}}{c_{t+1}^{i}}\right)^{\rho}\left(u_{t+1} r_{t+1}+\left(1-\delta\left(u_{t+1}\right)\right) q_{t+1}+\pi \lambda_{t+1}\left(u_{t+1} r_{t+1}+\phi q_{t+1}\left(1-\delta\left(u_{t+1}\right)\right)\right)\right)\right] \\
& \mathbf{1}_{\left\{z_{t}=b\right\}} \tilde{p}_{t}=\mathbf{1}_{\left\{z_{t}=b\right\}} E_{t}\left[\frac{\beta}{e^{b_{t+1}-b_{t}}}\left(\frac{c_{t}^{i}}{c_{t+1}^{i}}\right)^{\rho}\left(1+\pi \lambda_{t+1}\right) \tilde{p}_{t+1} \mathbf{1}_{\left\{z_{t+1}=b\right\}}\right], \\
& r_{t}=\alpha \frac{Y_{t}}{u_{t} K_{t}} \\
& w_{t}=(1-\alpha) \frac{Y_{t}}{(1-\pi) l_{t}} \\
& Y_{t}=\pi c_{t}^{i}+(1-\pi) c_{t}^{s}+\pi \frac{\left[u_{t} r_{t}+\phi q_{t}\left(1-\delta\left(u_{t}\right)\right)\right] K_{t}+\tilde{p}_{t} \mathbf{1}_{\left\{z_{t}=b\right\}} M}{1-\theta q_{t}} \\
& K_{t+1}=\left(1-\delta\left(u_{t}\right)\right) K_{t}+\pi \frac{\left[u_{t} r_{t}+\phi q_{t}\left(1-\delta\left(u_{t}\right)\right)\right] K_{t}+\tilde{p}_{t} \mathbf{1}_{\left\{z_{t}=b\right\}} M}{1-\theta q_{t}}
\end{aligned}
$$

and

$$
\lambda_{t}=\frac{q_{t}-1}{1-\theta q_{t}} .
$$

Detrending variables by $K_{t}$, we obtain

$$
\begin{gathered}
\hat{Y}_{t}=\bar{A} e^{a_{t}} u_{t}^{\alpha}\left((1-\pi) l_{t}\right)^{1-\alpha}, \\
\left(\hat{c}_{t}^{i}\right)^{-\rho}=\left(\hat{c}_{t}^{s}\right)^{-\rho}\left(1-l_{t}\right)^{\eta(1-\rho)},
\end{gathered}
$$




$$
\begin{gathered}
\eta \frac{\hat{c}_{t}^{s}}{1-l_{t}}=\hat{w}_{t} \\
q_{t}=E_{t}\left[\frac{\beta}{e^{b_{t+1}-b_{t}}}\left(\frac{\hat{c}_{t}^{i}}{\hat{c}_{t+1}^{i}} \frac{1}{g_{t}}\right)^{\rho}\left(u_{t+1} r_{t+1}+\left(1-\delta\left(u_{t+1}\right)\right) q_{t+1}+\pi \lambda_{t+1}\left(u_{t+1} r_{t+1}+\phi q_{t+1}\left(1-\delta\left(u_{t+1}\right)\right)\right)\right)\right] \\
m_{t}=\mathbf{1}_{\left\{z_{t}=b\right\}} E_{t}\left[\frac{\beta}{e^{b_{t+1}-b_{t}}}\left(\frac{\hat{c}_{t}^{i}}{\hat{c}_{t+1}^{i}} \frac{1}{g_{t}}\right)^{\rho}\left(1+\pi \lambda_{t+1}\right) m_{t+1} g_{t}\right] \\
r_{t}=\alpha \frac{\hat{Y}_{t}}{u_{t}}, \\
\hat{w}_{t}=(1-\alpha) \frac{\hat{Y}_{t}}{(1-\pi) l_{t}}, \\
\hat{Y}_{t}=\pi \hat{c}_{t}^{i}+(1-\pi) \hat{c}_{t}^{s}+\pi \frac{u_{t} r_{t}+\phi q_{t}\left(1-\delta\left(u_{t}\right)\right)+m_{t}}{1-\theta q_{t}} \\
g_{t}=1-\delta\left(u_{t}\right)+\pi \frac{u_{t} r_{t}+\phi q_{t}\left(1-\delta\left(u_{t}\right)\right)+m_{t}}{1-\theta q_{t}}
\end{gathered}
$$

and

$$
\lambda_{t}=\frac{q_{t}-1}{1-\theta q_{t}}
$$

where $m_{t} \equiv \tilde{p}_{t} \mathbf{1}_{\left\{z_{t}=b\right\}} M / K_{t}$. It is important that the system of equations summarized above does not have endogenous state variables. The endogenous variables are therefore determined by exogenous state $\left\{z_{t}, a_{t}, b_{t}\right\}$.

It is convenient to make the regime-dependence explicit:

$$
\begin{gathered}
\hat{Y}_{f, t}=\bar{A} e^{a_{t}}\left(u_{f, t}\right)^{\alpha}\left((1-\pi) l_{f, t}\right)^{1-\alpha}, \\
\hat{Y}_{b, t}=\bar{A} e^{a_{t}}\left(u_{b, t}\right)^{\alpha}\left((1-\pi) l_{b, t}\right)^{1-\alpha}, \\
\left(\hat{c}_{f, t}^{i}\right)^{-\rho}=\left(\hat{c}_{f, t}^{s}\right)^{-\rho}\left(1-l_{f, t}\right)^{\eta(1-\rho)}, \\
\left(\hat{c}_{b, t}^{i}\right)^{-\rho}=\left(\hat{c}_{b, t}^{s}\right)^{-\rho}\left(1-l_{b, t}\right)^{\eta(1-\rho)}, \\
\eta \frac{\hat{c}_{f, t}^{s}}{1-l_{f, t}}=\hat{w}_{f, t}, \\
\eta \frac{\hat{c}_{b, t}^{s}}{1-l_{b, t}}=\hat{w}_{b, t}, \\
r_{f, t}-\delta^{\prime}\left(u_{f, t}\right) q_{f, t}+\pi \lambda_{f, t}\left(r_{f, t}-\phi q_{f, t} \delta^{\prime}\left(u_{f, t}\right)\right)=0, \\
r_{b, t}-\delta^{\prime}\left(u_{b, t}\right) q_{b, t}+\pi \lambda_{b, t}\left(r_{b, t}-\phi q_{b, t} \delta^{\prime}\left(u_{b, t}\right)\right)=0,
\end{gathered}
$$




$$
\begin{aligned}
q_{f, t}= & E_{t}\left[\begin{array}{c}
\left(1-\sigma_{f}\right) \frac{\beta}{e^{\frac{b}{t+1-b_{t}}}}\left(\frac{\hat{c}_{f, t}^{i}}{\hat{c}_{f, t+1}^{i}} \frac{1}{g_{f, t}}\right)^{\rho} \\
\left(u_{f, t+1} r_{f, t+1}+\left(1-\delta\left(u_{f, t+1}\right)\right) q_{f, t+1}+\pi \lambda_{f, t+1}\left(u_{f, t+1} r_{f, t+1}+\phi q_{f, t+1}\left(1-\delta\left(u_{f, t+1}\right)\right)\right)\right)
\end{array}\right] \\
& +E_{t}\left[\begin{array}{c}
(33) \\
\sigma_{f} \frac{\beta}{e^{b_{t+1}-b_{t}}}\left(\frac{\hat{c}_{f, t}^{i}}{\hat{c}_{b, t+1}^{i}} \frac{1}{g_{f, t}}\right)^{\rho} \\
\left(u_{b, t+1} r_{b, t+1}+\left(1-\delta\left(u_{b, t+1}\right)\right) q_{b, t+1}+\pi \lambda_{b, t+1}\left(u_{b, t+1} r_{b, t+1}+\phi q_{b, t+1}\left(1-\delta\left(u_{b, t+1}\right)\right)\right)\right)
\end{array}\right],
\end{aligned}
$$

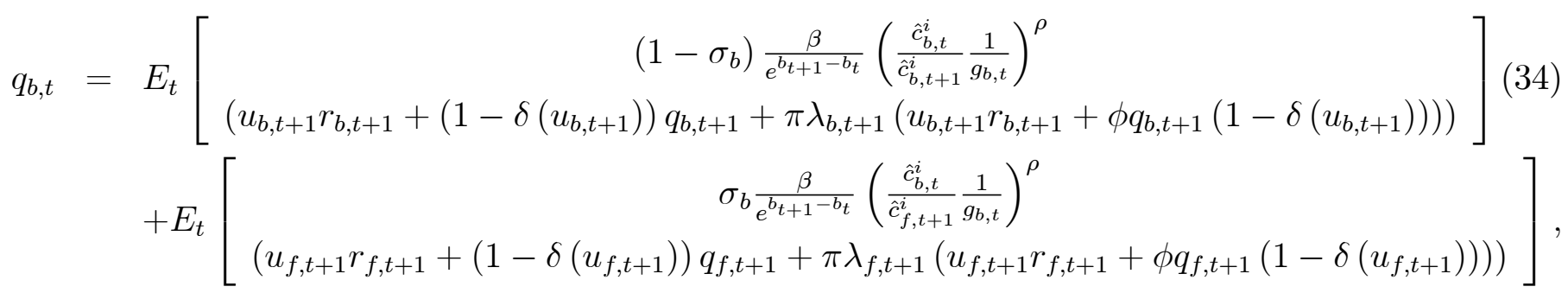$$
m_{f, t}=0,
$$

$$
\begin{gathered}
m_{b, t}=E_{t}\left[\left(1-\sigma_{b}\right) \frac{\beta}{e^{b_{t+1}-b_{t}}}\left(\frac{\hat{c}_{b, t}^{i}}{\hat{c}_{b, t+1}^{i}} \frac{1}{g_{b, t}}\right)^{\rho}\left(1+\pi \lambda_{b, t+1}\right) m_{b, t+1} g_{b, t}\right] \\
+E_{t}\left[\sigma_{b} \frac{\beta}{e^{b_{t+1}-b_{t}}}\left(\frac{\hat{c}_{b, t}^{i}}{\hat{c}_{f, t+1}^{i}} \frac{1}{g_{b, t}}\right)^{\rho}\left(1+\pi \lambda_{f, t+1}\right) m_{f, t+1} g_{b, t}\right] \\
r_{f, t}=\alpha \frac{\hat{Y}_{f, t}}{u_{f, t}} \\
r_{b, t}=\alpha \frac{\hat{Y}_{b, t}}{u_{b, t}} \\
\hat{w}_{f, t}=(1-\alpha) \frac{\hat{Y}_{f, t}}{(1-\pi) l_{f, t}}, \\
\hat{w}_{b, t}=(1-\alpha) \frac{\hat{Y}_{b, t}}{(1-\pi) l_{b, t}}, \\
\hat{Y}_{f, t}=\pi \hat{c}_{f, t}^{i}+(1-\pi) \hat{c}_{f, t}^{s}+\pi \frac{u_{f, t} r_{f, t}+\phi q_{f, t}\left(1-\delta\left(u_{f, t}\right)\right)+m_{f, t}}{1-\theta q_{f, t}} \\
\hat{Y}_{b, t}=\pi \hat{c}_{b, t}^{i}+(1-\pi) \hat{c}_{b, t}^{s}+\pi \frac{u_{b, t} r_{b, t}+\phi q_{b, t}\left(1-\delta\left(u_{b, t}\right)\right)+m_{b, t}}{1-\theta q_{b, t}} \\
g_{f, t}=1-\delta\left(u_{f, t}\right)+\pi \frac{u_{f, t} r_{f, t}+\phi q_{f, t}\left(1-\delta\left(u_{f, t}\right)\right)+m_{f, t}}{1-\theta q_{f, t}} \\
g_{b, t}=1-\delta\left(u_{b, t}\right)+\pi \frac{u_{b, t} r_{b, t}+\phi q_{b, t}\left(1-\delta\left(u_{b, t}\right)\right)+m_{b, t}}{1-\theta q_{b, t}}
\end{gathered}
$$




$$
\lambda_{f, t}=\frac{q_{f, t}-1}{1-\theta q_{f, t}}
$$

and

$$
\lambda_{b, t}=\frac{q_{b, t}-1}{1-\theta q_{b, t}}
$$

where subscripts $f$ and $b$ denote realizations of the variables in fundamental and bubble regimes, respectively; for instance, $\hat{Y}_{f, t}$ is the realization of $\hat{Y}_{t}$ in the fundamental regime. The regimedependent steady states are obtained as the solutions of the system of non-linear equations (25) to (46) under the assumption that both $a_{t}$ and $b_{t}$ are constant at zero. To capture the effects of $a_{t}$ and $b_{t}$, we linearize the equations (25) to (46) around the regime-dependent steady states and obtain the impulse response functions.

\subsection{Regime-Switching Partial-Collapse Model}

We examine variants of our regime-switching model in which not all the bubbly assets collapse. It has no fundamental regime, but has two bubbly regimes with different amounts of bubbly assets. We call them high-bubble $(\mathrm{H})$ and low-bubble $(\mathrm{L})$ regimes respectively, in each of which $M$ and $\left(1-\delta_{M}\right) M$ units of bubbly assets exist respectively. A fraction $\delta_{M} \in(0,1)$ of randomly chosen bubbly assets physically disappears when the regime switches from the high-bubble regime to the low-bubble one, and $\delta_{M} M$ units of a new vintage of bubbly assets are created when the regime switches to the other direction. We omit the productivity and preference shocks to simplify the analysis.

Green circles and crosses in Figure 11 show the regime-dependent capital growth $g_{t}=K_{t+1} / K_{t}$ in this model. We set the depreciation rate of the bubbly asset $\delta_{M}$ at $\delta_{M}=0.999$. Therefore, nearly all the bubbly assets suddenly disappear at the time of the partial collapse. Nonetheless, the regime-dependent capital growth in the partial-collapse model does not resemble its counterpart in the original model plotted in red circles and crosses in the same figure. Specifically, the distance between green circles and crosses is shorter than the distance between red circles and crosses.

To see why, Figure 12 plots the regime-dependent bubble size relative to capital stock. In the partial-collapse model, a sizable bubble exists not only in the high-bubble regime but also in the low-bubble regime. The mechanism is simple; even if most of the bubbly assets lose value (physically disappear in the model), the rest of the bubbly assets appreciate because liquid assets become scarce and demand for the rest of the bubbly assets rises as a result. This general equilibrium effect stabilizes the bubble size, and so does the impact of the partial collapse on growth. Our benchmark model is different in this respect; because we consider the entire collapse of bubbles, the supply of bubbly assets is zero in the fundamental regime, and therefore, the aforementioned general equilibrium effect is absent. As a consequence, the entire collapse of bubbles has a strong impact on growth (Figure 11).

Green lines in Figure 13 show the regime-dependent capital growth in the model with multiple 


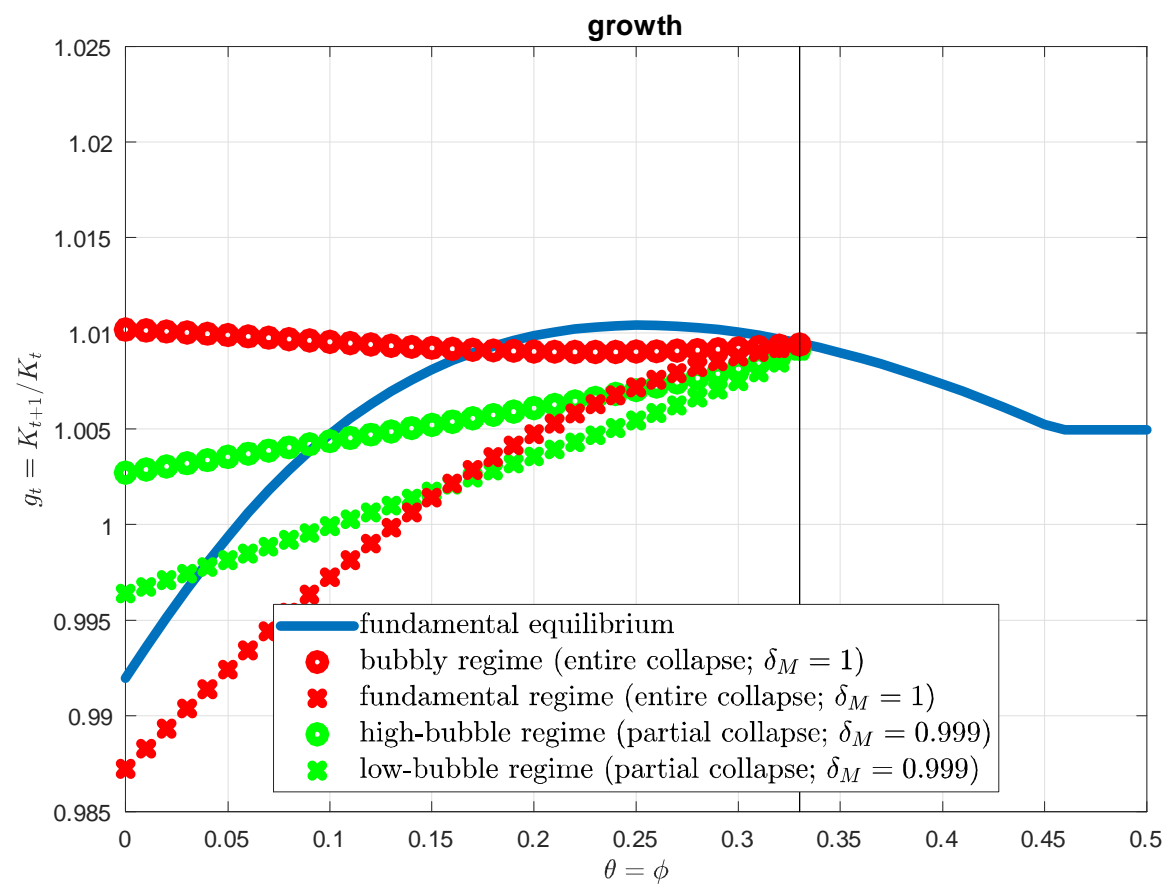

Figure 11: Impact of Partial Collapse on Growth

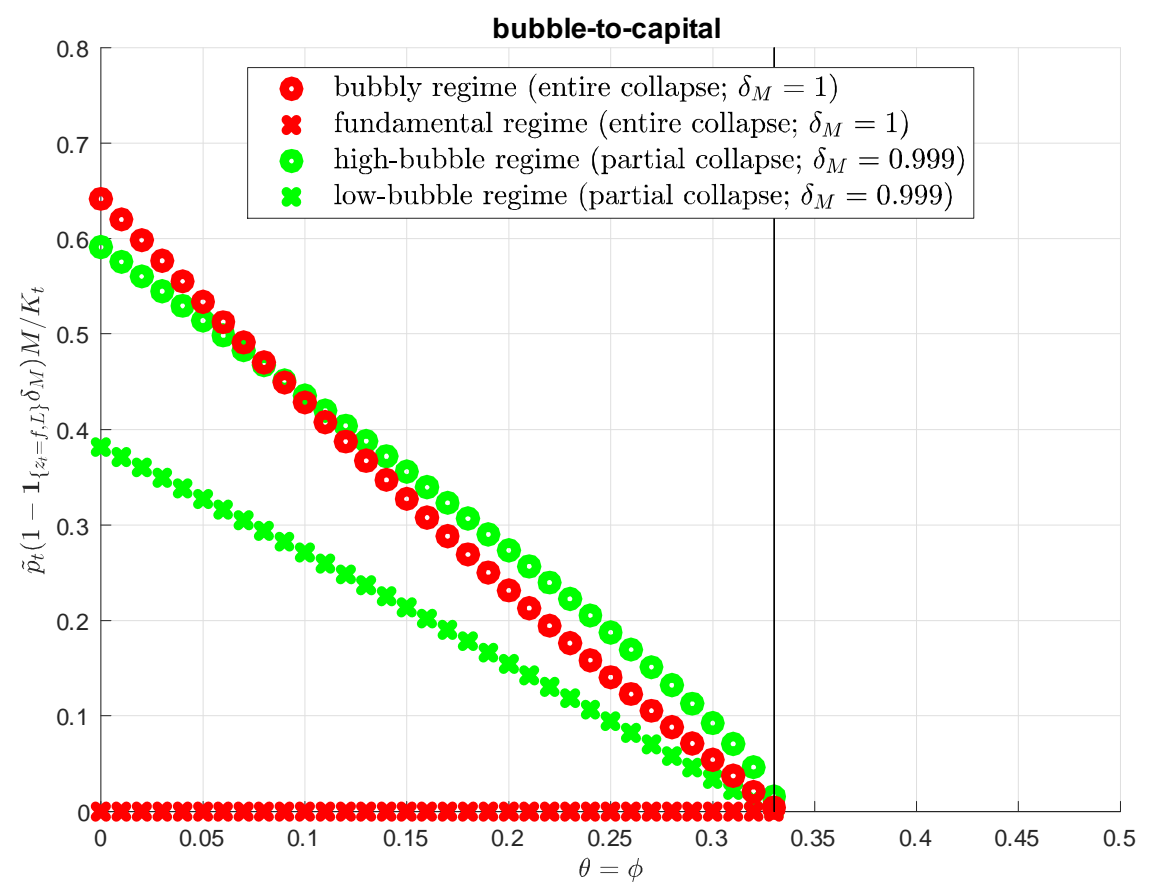

Figure 12: Impact of Partial Collapse on Bubble Size 


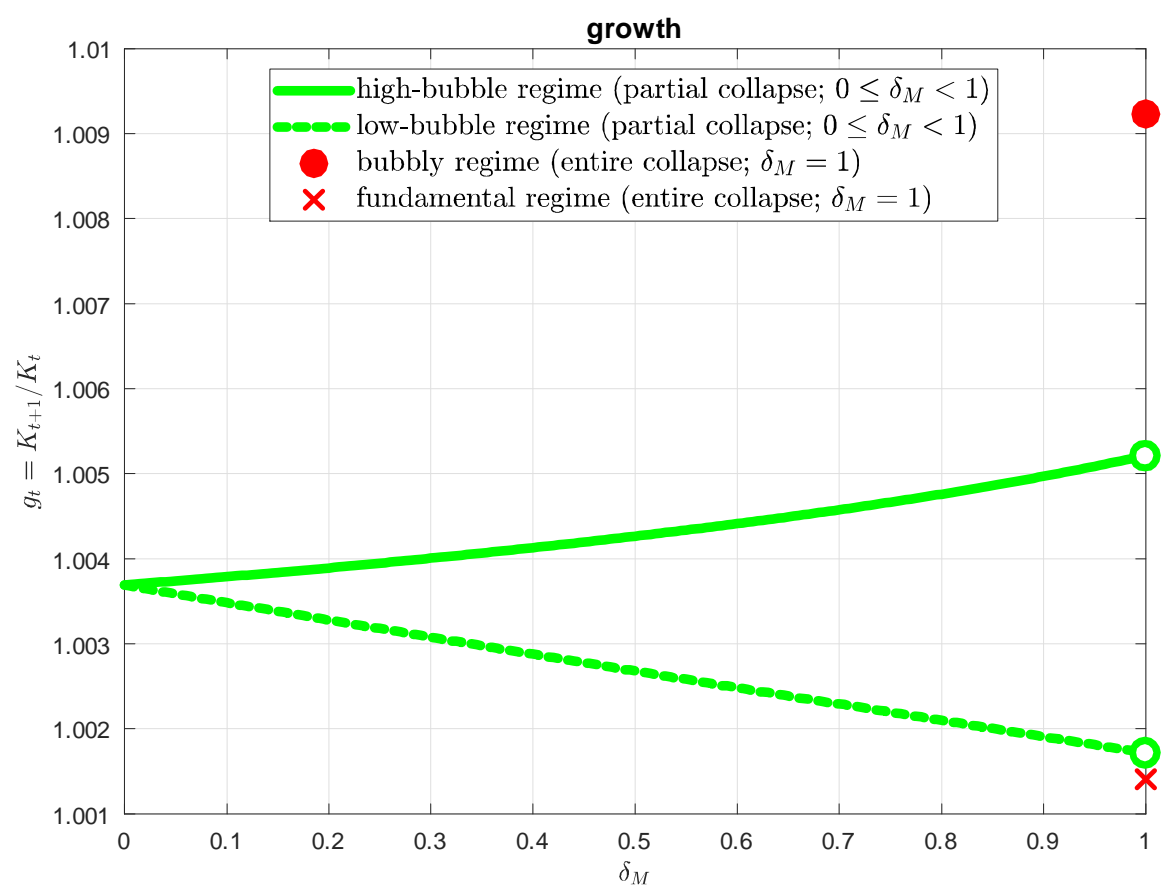

Figure 13: Bubbly-Asset Depreciation and Growth

partial collapses as a function of $\delta_{M}$ at a moderate level of financial frictions. ${ }^{36}$ At $\delta_{M}=1$, we plot the regime-dependent capital growth in the model with multiple entire collapses (our benchmark model). We see no sign of "convergence" from the model with multiple partial collapses to the model with multiple entire collapses as $\delta_{M}$ approaches 1 , but there is a discrete jump at $\delta_{M}=1$. This is the same type of non-linearity that Brunnermeier and Sannikov (2014), He and Krishnamurthy (2013), and Gertler and Kiyotaki (2015) emphasize to account for the financial crisis.

\subsection{Existence Condition}

As we discussed in the paper, a bubbly equilibrium may or may not exist depending on the tightness of financial constraints. In this section, we highlight other elements that may affect the existence of a bubbly equilibrium.

To simplify the analysis, let us assume for a moment that the economy is always in the bubbly regime. Let us assume that $a_{t}=b_{t}=0$ for all $t$ too. Under these assumptions, equation (22) is rewritten as follows:

$$
m=\hat{\imath}(1-\theta q)-u r-\phi q(1-\delta(u))
$$

\footnotetext{
${ }^{36}$ We set $\theta=\phi=0.15$. But the main message does not change at different values of $\theta$ and $\phi$.
} 
where $m$ and $\hat{\imath}$ are steady-state values of $m_{t}=\tilde{p}_{t} M / K_{t}$ and $\hat{\imath}_{t}=i_{t} / K_{t}$, respectively. The first term in the right-hand side is the down payment each investor needs to pay to conduct investment $\hat{\imath}$. The second term is the rental rate of capital, and the third term is the amount of liquidity the investor can obtain from undepreciated old capital. Therefore, this equation says that bubbles exist $\left(\tilde{p}_{t}>0\right.$, or the left-hand side is positive) if and only if the amount of liquidity an investor can withdraw from capital is less than the amount of liquidity investors need to undertake investment.

To convey more intuition, let's assume that utilization is 1 and there is full depreciation. Under these assumptions, equation (47) is rewritten as

$$
m=\frac{g}{\pi}(1-\theta q)-r
$$

$\pi \hat{\imath}=g$ holds because of full depreciation, where $g$ is the steady-state value of $g_{t}=K_{t+1} / K_{t}$, which is identical to the growth rate of the economy in the current setup. Bubbles are valued when the rental rate of capital is sufficiently low. This implication is in line with the previous work on bubbles. If we further assume that $\theta$ is equal to $\theta=0$ (equity finance is impossible) and $\pi$ is equal to $\pi=1$ (everyone can invest), the first term in the right-hand side collapses to $g$, and $g>r$ is the familiar dynamic inefficiency condition for the existence of bubbles in OLG models.

If $\theta$ is strictly positive, investors can issue equity to some extent. By making the first term in the right-hand side smaller, a larger value of $\theta$ makes it more difficult to support bubbles. This implication is also in line with previous work; e.g., Tirole (1982) shows that bubbles cannot arise in infinite horizon economies in which agents can borrow and lend freely. Increasing $\pi$ makes the first term in the right-hand side smaller too, because in the aggregate, a larger number of people having investment opportunities is similar to relaxing the financial constraint. In other words, a tight enough financial friction is necessary for the economy to have a bubbly equilibrium.

Let us briefly discuss the existence condition in a more general setup. Assuming full depreciation and fixing the utilization rate at one in the regime-switching recurrent bubble model, we arrive at the following expression,

$$
m_{b}=\hat{\imath}_{b}\left(1-\theta q_{b}\right)-r_{b}
$$

Other things being equal, bubbles are sustained ( $m_{b}$ is positive) when the liquidity constraint is tight, the rental price of capital is low, and/or the investment (and hence the growth rate) in the bubble regime is high. These implications are similar to those in the permanent-bubble case.

\subsection{Data}

In this section, we explain the observables used to estimate the model. The data consist of quarterly GDP growth and the stock-market-to-GDP ratio for the period 1984.Q1-2017.Q4. The data come from the St. Louis Fed's FRED database. For the stock-market-to-GDP ratio, we 
use the quarterly not seasonally adjusted Wilshire 5000 Full Cap Price Index series. The raw unfiltered series was used to compute GDP growth. We pre-filtered the stock market-to-GDP ratio series with the HP filter to remove the trend in the data that is not present in our model; see the main text for a discussion of the properties of the filtered series. We think that this approach is reasonable because we are interested in understanding how the fluctuations around this trend are influenced by the presence or the absence of bubbles. Furthermore, this de-trending approach is standard in policy institutions such as the Federal Reserve System when it analyzes the evolution of credit in the economy (Bassett, Daigle, Edge, and Kara (2015)). The Bank of Japan takes a similar approach too. Specifically, in its biannual publication surveying the financial system, ${ }^{37}$ the bank constructs the "heat map" from several financial indicators, including stock market value, on which abnormal deviations of a variable from its trend are read as a sign of over-heating and painted in red.

\subsection{Solution Method}

The solution and estimation of the model requires a series of steps that we describe next.

1. We de-trend the model's equilibrium conditions by the stock of capital, resulting in a stationary model. It is easy to see that given the structural shocks and the regime today, the model is entirely forward looking (equations (25) to (46) in Section 8.1.3).

2. Let $X_{t}^{f}$ and $Y_{t}^{f}$ denote the vectors containing the states and controls in the fundamental regime. Similarly, $X_{t}^{b}$ and $Y_{t}^{b}$ denote the vectors containing the states and controls in the bubbly regime. Then the de-trended model can be written as

$$
\begin{aligned}
E_{t} \Gamma_{f}\left(X_{t}^{f}, Y_{t}^{f}, X_{t+1}^{f}, Y_{t+1}^{f}, X_{t+1}^{b}, Y_{t+1}^{b}\right) & =0 . \\
E_{t} \Gamma_{b}\left(X_{t}^{b}, Y_{t}^{b}, X_{t+1}^{f}, Y_{t+1}^{f}, X_{t+1}^{b}, Y_{t+1}^{b}\right) & =0 .
\end{aligned}
$$

That is, we stack the model's equilibrium equations conditional on being in the fundamental and the bubbly regimes. Note that the notation makes clear that the economy may switch to a different regime tomorrow. The functional equations describing the equilibrium conditions are captured by $\Gamma_{f}(\cdot)$ and $\Gamma_{b}(\cdot)$.

3. We compute the steady state (w/o structural shocks) of each regime $\left(X^{f}, Y^{f}, X^{b}, Y^{b}\right)$ by shutting down the structural shocks but preserving the regime switches. In other words, we look for $X^{f}, Y^{f}, X^{b}, Y^{b}$ that solve the system:

$$
\begin{aligned}
\Gamma_{f}\left(X^{f}, Y^{f}, X^{f}, Y^{f}, X^{b}, Y^{b}\right) & =0 . \\
\Gamma_{b}\left(X^{b}, Y^{b}, X^{f}, Y^{f}, X^{b}, Y^{b}\right) & =0 .
\end{aligned}
$$

\footnotetext{
${ }^{37}$ Financial System Report, https://www.boj.or.jp/en/research/brp/fsr/index.htm/.
} 
In doing so, our method respects the probability of switching from the fundamental steady state to the bubbly steady state and vice versa.

4. We perturb the model around the steady states and solve the resulting system to obtain the laws of motion for the endogenous states and controls. For simulations and estimation, we use a first-order perturbation approach (Schmitt-Grohe and Uribe (2004)).

5. It can be shown that the first-order approximation of the model can be written compactly as follows:

$$
\mathbb{X}_{t}=\Lambda_{x} \mathbb{X}_{t-1}+\Omega_{x} \Xi_{x, t}
$$

Here, $\mathbb{X}_{t}=\left[X^{f}, Y^{f}, X^{b}, Y^{b}\right]^{\prime}$ and $\Xi_{x, t}$ contains the structural innovations at time $t$.

6. We supplement the transition equation in the previous point with a measurement equation of the form:

$$
\mathbb{Y}_{t}=\Lambda_{y} \mathbb{X}_{t}+\Omega \Xi_{y, t}
$$

The matrix $\Lambda_{y}$ makes the necessary transformations to make the model's variables compatible with the observables in the data collected in vector $\mathbb{Y}_{t}$. We allow for classical measurement errors as captured by $\mathbb{Y}_{t}$.

7. To compute the likelihood of the model, we use the nonlinear filter discussed in chapter 5 in Kim and Nelson (1999).

8. The Bayesian estimation is implemented following Fernandez-Villaverde, Rubio-Ramirez, and Schorfheide (2016).

\subsection{Impulse Responses}

Table 3 reports the impulse response functions of variables not discussed in the paper. Responses to a one-standard-deviation innovation to a productivity shock $\left(S D_{a}=0.01\right)$ and a preference shock $\left(S D_{b}=0.08\right)$ are reported. Their autocorrelations are 0.9 and 0.5 , respectively. We report contemporaneous responses on impact of the shock alone, because they are sufficient to summarize the impulse responses for the variables reported in the table. Remember that there are no endogenous state variables in our model once endogenous variables with trend are divided by $K_{t}$ (see equations (25) to (46)). Therefore, both the regime $z_{t} \in\{f, b\}$ and the levels of the productivity and preference shocks $\left\{a_{t}, b_{t}\right\}$ are sufficient to pin down detrended endogenous variables.

A positive productivity shock (a rise in $a_{t}$ ) increases output, consumption, investment, and hours worked simultaneously. In contrast, a positive preference shock (a rise in $b_{t}$ ) increases investment but decreases consumption. Remember that the preference shock decreases the level of the subjective discount factor on impact but it is mean reverting. Hence, after the shock, households end up putting large weights to the utility flows in the distant future relative to those 


\begin{tabular}{ccccc} 
& \multicolumn{2}{c}{ Bubbly Regime } & \multicolumn{2}{c}{ Fundamental Regime } \\
\hline & Productivity & Preference & Productivity & Preference \\
\hline output-to-capital & $1.18 \%$ & $-0.00 \%$ & $1.10 \%$ & $-0.05 \%$ \\
consumption-to-capital & $1.06 \%$ & $-0.28 \%$ & $1.03 \%$ & $-0.26 \%$ \\
investment-to-capital & $1.55 \%$ & $0.84 \%$ & $1.38 \%$ & $0.87 \%$ \\
hours & $0.09 \%$ & $0.21 \%$ & $0.05 \%$ & $0.16 \%$ \\
utilization & $0.36 \%$ & $-0.42 \%$ & $0.21 \%$ & $-0.47 \%$ \\
capital price & $0.77 \%$ & $0.62 \%$ & $0.95 \%$ & $0.67 \%$ \\
bubble-to-capital & $1.83 \%$ & $0.79 \%$ & - & - \\
capital growth & $0.05 \%$ & $0.06 \%$ & $0.04 \%$ & $0.04 \%$ \\
\hline
\end{tabular}

Table 3: Effects of Productivity and Preference Shocks

in the near future. Therefore, households become effectively more patient than before, hence increasing investment and decreasing consumption. Asset prices also increase because of the discount factor channel.

Comparing responses across regimes, we see larger responses in the bubbly regime than in the fundamental regime. Bubbles amplify the impact of the shocks because the bubble size positively responds to the shocks, supplying more liquidity to the economy. But regime-dependence in impulse responses is moderate.

\subsection{Alternative Identification Strategies}

In this section, we show the impact of alternative identification strategies on our empirical results. For our first check, we use quarterly U.S. data on GDP growth and the credit-to-GDP ratio. Similar to the stock market value, the credit-to-GDP ratio in the model is higher during bubbly episodes than during the fundamental ones. Figure 14 presents the estimated probability of the economy being in the bubbly regime. It shows that the economy spent more time in the fundamental regime prior to the 2000s. This means that during the first 15 years of the sample, growth was driven by exogenous productivity shocks (not shown), not a surprise given the moderate credit-to-GDP ratio in the data.

The economy starts the 2000s in the fundamental regime, but as credit expands rapidly, the probability of being in the bubbly regime rises. By mid-2005, the bubble is becoming more likely, with a smoothed probability above 50\%. Between 2007 and early 2009, our exercise reveals that the bubble was in full swing. Importantly, growth is bubble-driven in this period, which is an interesting contrast to the productivity-driven growth in the 1990s. At its peak, credit in the data is explained by a combination of bubbles and a favorable productivity shock. The bubble disappears in the early 2010s.

During the initial phase of the Great Recession, credit is in correction territory but still high compared to the 1990s. As a consequence, our approach identifies this stage of the crisis as the result of a sharp decline in investment demand due to an exogenous shock to preferences. But 


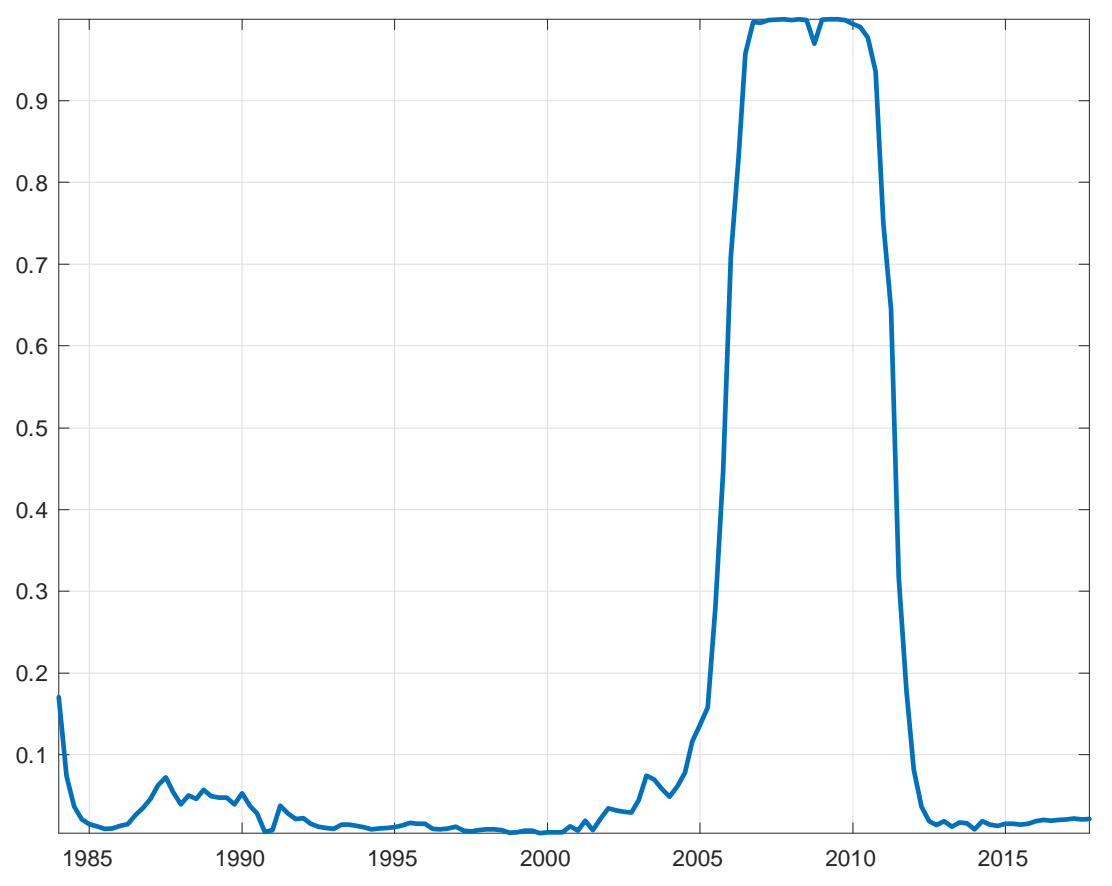

Figure 14: Probability of Bubbly Regime

as the contraction in credit continued and the economy grew at lackluster rates, the fundamental regime becomes more likely to the point where it is the prevalent regime since 2011. It is worth noting that our estimate of the bubbly episode lasts longer than other researchers have found (Jorda, Schularick, and Taylor (2015)). This is due to the evolution of aggregate credit, peaking at the end of 2008 and slowly retrenching afterward, the latter of which Ivashina and Scharfstein (2010) attribute to the extensive use of existing lines of credit during 2009 and 2010. Ideally, we would use newly issued credit rather than total credit to better capture the narrative behind the crisis. However, to the best of our knowledge, such data are not available at the frequency and length required for our purpose.

For the financial constraints of $\theta=\phi=0.19$ considered in the main text, the average growth rates and credit-to-GDP are off the values in the data seen during the bubbly episode in the 2000s. One possibility, used in the paper, is to introduce a constant and estimate it to offset the difference. Alternatively, one can change the financial constraints to match the average growth rate during the presumptive bubbly period, with the caveat that we impose the dates when the bubble exists a priori. Figure 15 shows the estimated path of the probability of the fundamental (upper panel) and bubbly (lower panel) regimes under this specification. Clearly, the paths are consistent with those reported in the paper.

In the main text, we estimate the regimes using the sample 1984.Q1-2017.Q4. One can extend 

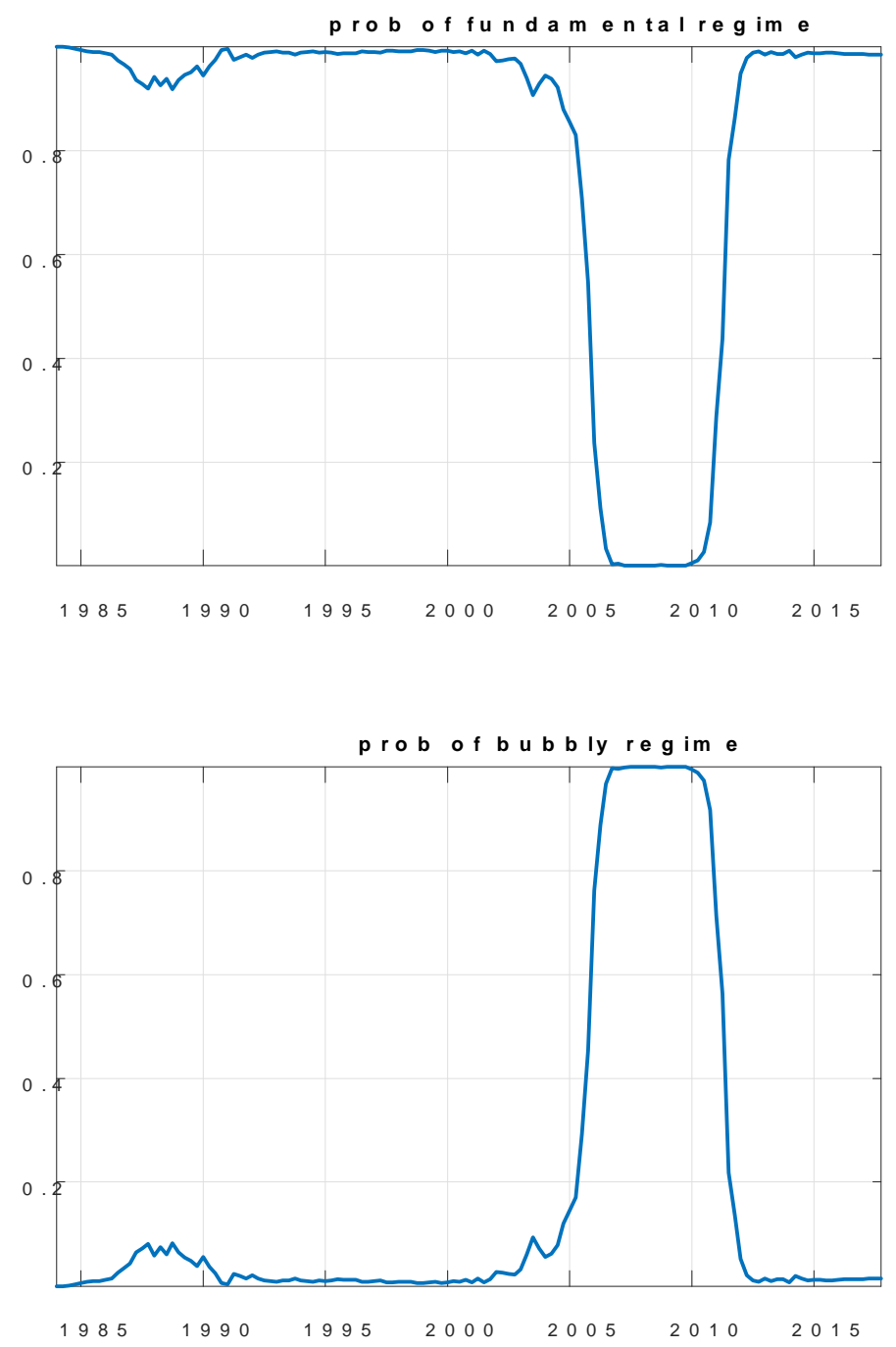

Figure 15: Regime Probabilities with Tighter Liquidity 

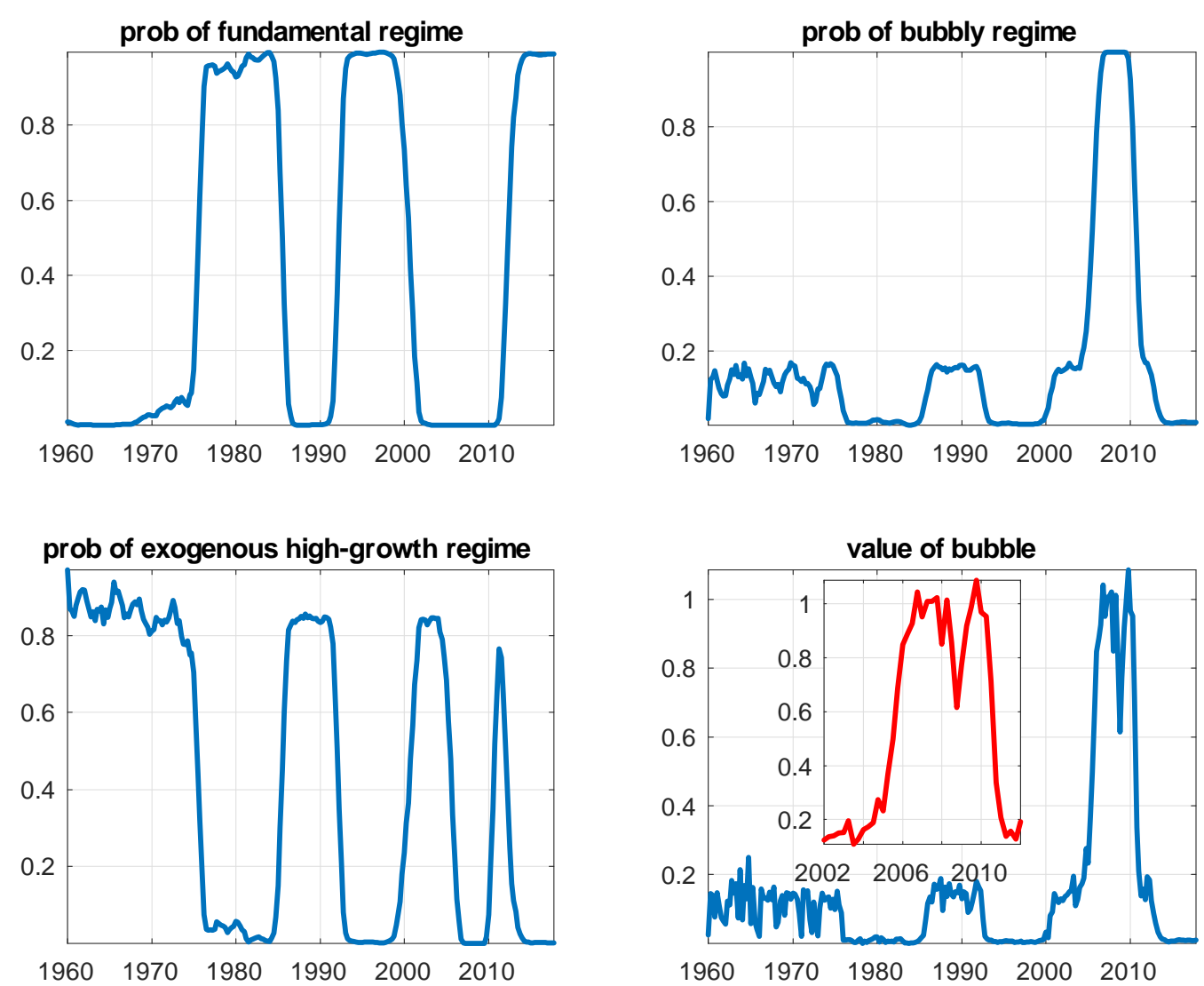

Figure 16: Regime Probabilities Extended Sample

the sample to include the pre-Great Moderation era 1960.Q1-1983.Q4 but this brings a complication. Growth was strong during that period and credit-to-GDP was above average. Through the lens of our benchmark model, this points to a bubble. However, most economic observers would agree that there was no bubble during those years. To cope with this issue, we add a third regime that allows for high growth and average credit. Figure 16 shows the probabilities of each regime from this alternative model. As one can see, the main message remains. The high growth/high credit of the 2000s was most likely associated with the occurrence of a bubble in the economy. We also see that the economy spent most of the 1960s and 1970s in the third regime. 